\title{
Biogeociclos: Uma visão molecular das enzimas e dos mecanismos envolvidos nos ciclos dos elementos: Parte I
}

\author{
CARLA CARNEIRO ${ }^{1,2}$ E JOSÉ J. G, MOURA
}

\author{
Parte 1: Biogeociclo do Azoto \\ Título corrente: Biogeociclos dos ele- \\ mentos
}

Palavras chave: Ciclos dos elementos, Azoto, Enxofre, Carbono, Hidrogénio

\begin{abstract}
Nota prévia
A circulação dos elementos químicos no planeta é um processo complexo com muitas e variadas vertentes. Os vários ciclos elementares são muito mais do que simples reacções químicas. São em parte biológicos e em parte geoquímicos, pois envolvem a participação de microrganismos e estão associados a grupos de elementos metálicos. Uma variedade de enzimas e múltiplos transportadores electrónicos (que com estas interactuam) asseguram a catálise, passo a passo, por formação de intermediários chave.
\end{abstract}

As etapas chave destes ciclos biogeoquímicos são catalisados por enzimas que dependem de ferro, manganês, molibdénio, cobre, níquel, entre outros e têm levantado importantes questões na área da Química Bioinorgânica, nos processos de conservação de energia e nas relações estrutura/função. 0 esclarecimento destas e de outras questões surgiu, essencialmente nos últimos três anos, por obtenção da estrutura cristalográfica duma variedade de enzimas incluindo estruturas das enzimas com o substrato ou com o produto ligado. Estes novos dados contribuiram, assim, para um progresso significativo no conhecimento do papel dos centros metálicos envolvidos na catálise, revelando a sua arquitectura, para além de aspectos estruturais globais que permitiram uma interpretação mecanística dos processos que compõem os vários ciclos biogeoquímicos. Estes são constituídos por processos assimilativos, quando se realiza a incorporação de um determinado elemento, sob a forma de matéria orgânica, ou respiratórios, se associados à obtenção de energia, utilizando as várias espécies como aceitadores electrónicos e/ou dissimilativos associados à dissipação de energia ou poder redutor ou à detoxificação.

Muito embora a respiração aeróbia seja energeticamente mais favorável uma variedade de compostos (orgânicos e inorgânicos) pode ser utilizada como aceitador terminal de electrões, para além do oxigénio (figura 1). A capacidade de efectuar uma respiração anaeróbia permite, deste modo, a alguns microrganismos, a sobrevivência em nichos particulares.

É objectivo deste artigo rever aspectos estruturais das enzimas envolvidos nos ciclos dos elementos. Os ciclos não são apresentados de modo exaustivo, mas procura-se pôr em evidência as partes dos ciclos para as quais há um conheci- mento detalhado da estrutura tridimensional do biocatalisador envolvido. Mais ainda, são apresentadas hipóteses mecanísticas que resultam, muitas delas, da análise estrutural. Os avanços da biologia molecular e das técnicas de análise estrutural permitem, que neste momento, haja disponível um conjunto de informaçăo que possibilita uma análise detalhadas das relações estrutura e função dos biocatalisadores que controlam as transformações occorentes nos ciclos.

0 artigo é dividido em 3 partes:

1 - Biogeociclo do AzOTO

2- Biogeociclo do ENXOFRE

3- Biogeociclo do CARBONO e HIDROGÉNIO

\section{O ciclo do azoto}

\subsection{Introdução}

No ciclo biogeoquímico do azoto (figura 2) participam uma série de enzimas que catalisam a interconversão do azoto inorgânico entre diferentes estados de oxidação (+5 a -3), a sua assimilação (como matéria orgânica) e a respectiva mineralização (reacção inversa) (Richardson et al., 1998; Richardson e Watmough, 1999).

Nos procariotas, as várias reacções de oxidaçāo-redução, com excepção da

${ }^{1}$ REQUIMTE, Departamento de Quimica, Faculdade de Ciências e Tecnologia, Universidade Nova de Lisboa, 2829-516 Monte de Caparica, Portugal Tel: +351-21-2948382 Fax: +351-21-2948550 e-mail: jose.moura@dq.fct.unl.pt, web www.dq.fct.unl.pt/bioin/

${ }^{2}$ Morada presente: Departamento de Sistemas e Informática, Escola Superior de Tecnologia, Instituto Politécnico de Setúbal, Rua Vale de Chaves, Estefanilha, 2910-761 Setúbal 


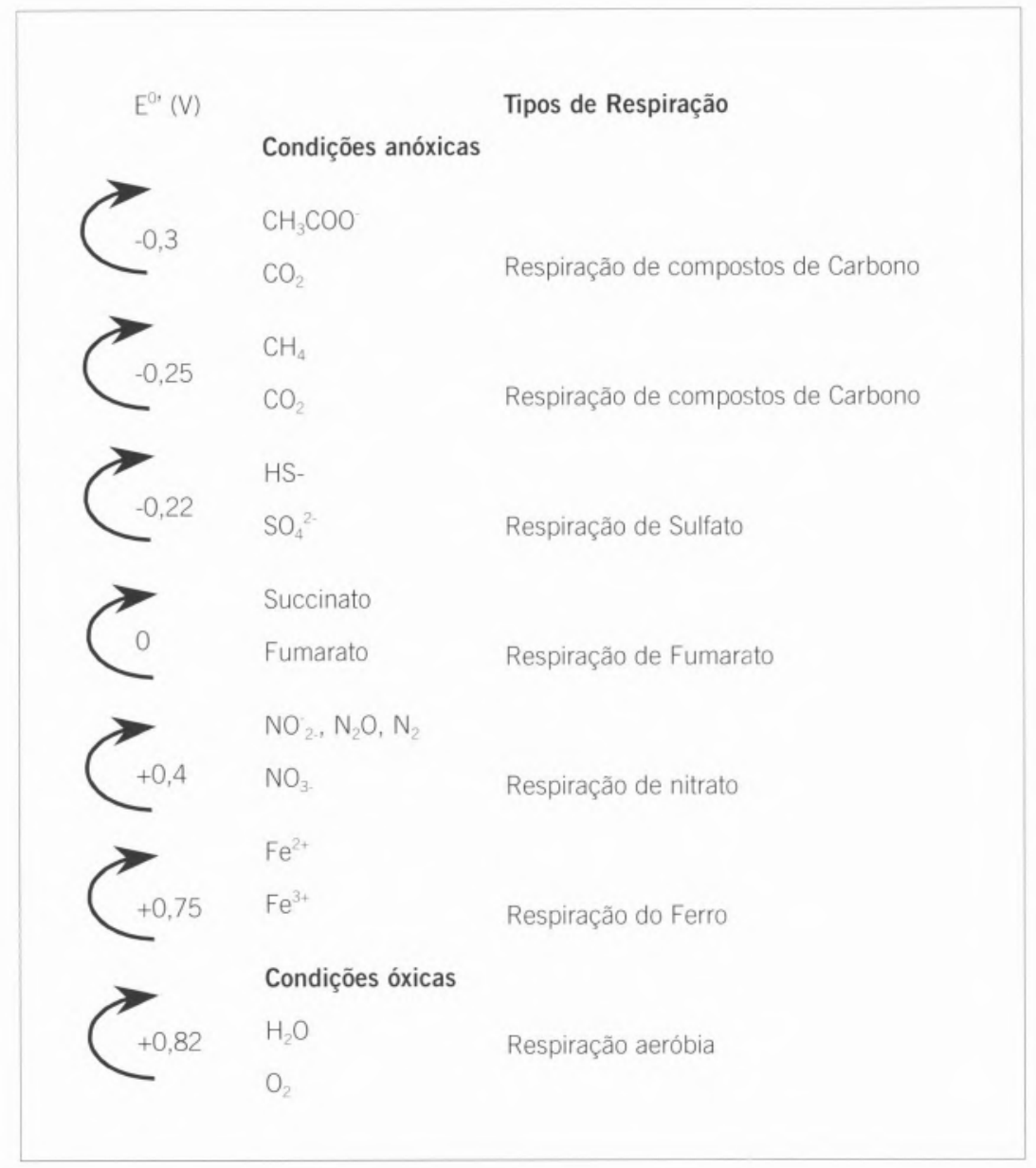

figura 1 Exemplos de respiração anaeróbia (Adaptado de Madigan et al., 2000)

reacção de fixação (que envolve uma enzima citoplasmática que requer ATP), estão associadas a transportadores de membrana na cadeia respiratória e, consequentemente, à síntese de adenosina trifosfato (ATP). Os passos oxidativos (amónia a nitrito e nitrito a nitrato) envolvem a doação de electrões ao oxigénio, via proteínas membranares, enquanto que as reacções de redução (nitrato a azoto molecular) envolvem o fluxo de electrões provenientes de várias cadeias de transporte electrónico (Ferguson, 1998).
A capacidade de fixar o azoto molecular é restrita aos procariotas dos domínios Bacteria e Archaea, denominados organismos diazotróficos. A nitrificação é o processo pelo qual a amónia é oxidada a nitrito; na nitrificação autotrófica, a amónia é utilizada como fonte de crescimento, enquanto que a nitrificação heterotrófica está associada à dissipação de energia. A sequência pela qual o nitrato e o nitrito são reduzidos, via óxidos azotados gasosos, a azoto molecular é denominada desnitrificação. 0 nitrato e o nitrito podem também ser reduzidos com fins assimilativos ou para detoxificação do nitrito por acção de enzimas citoplasmáticas, num processo não energético (Richardson et al., 1998; Richardson e Watmough, 1999; Schmid et al., 2001).

\subsection{Caracterização molecular de enzimas do ciclo do azoto}

\subsubsection{Nitrogenase (passo 1)}

A nitrogenase catalisa a redução do azoto molecular a amónia num processo dependente de ATP, de acordo com a seguinte equação:

$\mathrm{N}_{2}+6 \mathrm{H}^{+}+6 \mathrm{e} \rightarrow 2 \mathrm{NH}_{3}$

A nitrogenase catalisa também a redução de protões a hidrogénio molecular, à custa da hidrólise da ATP, e a redução de uma série de substratos não fisiológi$\cos$ (acetileno, azida, cianeto e cloropropeno) (Schmid et al., 2001).

A nitrogenase de Azotobacter ( $A z$. ) vinelandii (figura 3) é composta por duas

figura 2 Ciclo biogeoquímico do azoto. O azoto atmosférico $\left(\mathrm{N}_{2}\right)$ pode ser reduzido a amónid $\left(\mathrm{NH}_{3}\right)$ por acção da nitrogenase (passo 1). A amónia pode ser incorporada como matéria orgânica ou ser sequencialmente oxidada, via hidroxilamina, a nitrito $\left(\mathrm{NO}_{2}^{-}\right)$, por catálise da MOA (passo 2) e da OHA (passo 3), respectivamente, e a nitrato $\left(\mathrm{NO}_{3}^{-}\right)$, por intermédio da oxidase do nitrito (passo 4) (desnitrificação). Por sua vez, o nitrato pode ser utilizado como fonte de azoto para biossinteses, ou ser sequencialmente reduzido, via nitrito, a óxido nítrico (NO) e o óxido nitroso $\left(\mathrm{N}_{2} \mathrm{O}\right)$ a azoto molecular $\left(\mathrm{N}_{2}\right)$, por acção conjunta da NAR (ou NAP), NiR (ou CuNiR), NOR e NOS, respectivamente (passos 5 a 8). O nitrito pode, por sua vez, ser reduzido a amónia, por catálise da ccNiR (passo 6) (Adaptado de Ferguson, 1998). A nomenclatura das enzimas é indicada no texto. 


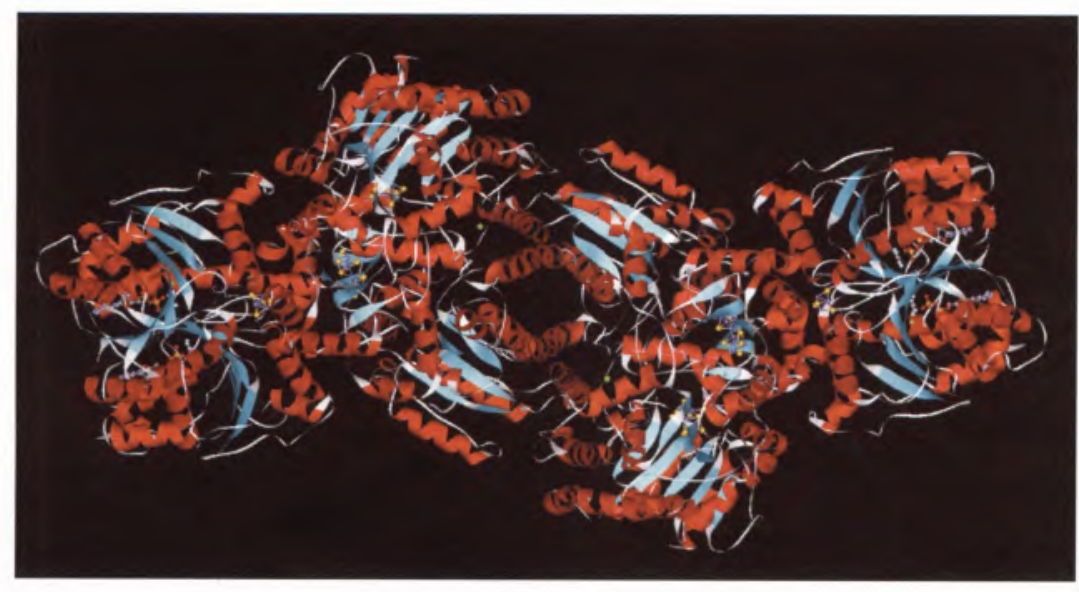

proteinas citoplasmáticas: a proteína de ferro ( $\mathrm{Fe}$ ), um homodímero de $63 \mathrm{kDa}$ e a proteina de molibdénio e ferro (FeMo), um heterotetrâmero $(\alpha 2 \beta 2)$ de 240 kDa em que cada subunidade $\alpha$ e $\beta$ possui $60 \mathrm{kDa}$. A proteína de $\mathrm{Fe}$, ou componente $I$, possui um único centro de [4Fe-4S] e liga duas moléculas de ATP; transmite electrões, a partir de uma proteína doadora, a flavodoxina, para a proteína de FeMo, ou componente I, que contém o sítio de ligação e de redução do azoto molecular. A proteína de FeMo possui, por dímero, dois tipos de centros de ferro-enxofre: um é o agregado $P$, um centro de [8Fe-7S], um duplo cubano, e o outro incorpora molibdénio (1Mo:7Fe:9S:1 homocitrato). Adicionalmente, possui dois catiões ligados, $\mathrm{Ca}^{2+}$ ou $\mathrm{Mg}^{2+}$, aos quais foi atribuido um papel estrutural. As nitrogenases alternativas diferem das nitrogenases tradicionais, no facto do molibdénio da pro- teína de FeMo ser substituido por vanádio (proteína FeV) ou por um ferro adicional (proteína FeFe) (Ferguson, 1998; Schmid et al., 2001).

\section{A proteína de FeMo}

Apesar de não existir semelhança na sequência de aminoácidos das duas subunidades ( $\alpha$ e $\beta$ ) do tetrâmero, estas apresentam um enrolamento muito semelhante que consiste em três domínios do tipo folha $\beta$ paralela/hélice $\alpha$. Na subunidade $\alpha$, o co-factor de FeMo ocupa o topo de uma fenda existente na interface dos três domínios, enquanto que o agregado $\mathrm{P}$ está localizado na interface, entre as subunidades $\alpha$ e $\beta$, protegido do solvente. No entanto, o ambiente em seu redor contém vários resíduos polares e carregados. Cada subunidade $\beta$ possui um catião ligado, presumivelmente um cálcio, coordenado por resíduos de ambas as subunidades. A ex- figura 3 Representação esquemática da nitrogenase hetero-octamérica de Az. vinelandii estabilizada com ADP.AIF4. Os cofactores e o ião cálcio (a verde) estâo representados por modelos "stick and ball"(Adaptado de Schmid et al., 2001). tensa interacção entre as subunidades $\alpha$ e $\beta$ sugere que cada um dos dímeros ab forma uma unidade funcional pelo que se pode considerar o tetrâmero como sendo um dímero de dímeros (figura 4) (Schmid et al., 2001).

0 agregado $\mathrm{P}$, um centro de [8Fe-7S], alterna a sua coordenação, consoante o estado de oxidação da proteína de FeMo. No estado oxidado $\left(P_{0 x}\right)$ (figura $5 A$ ), este pode ser descrito como sendo constituido por um centro de [4Fe-4S] e um centro de [4Fe-3S] (predominantemente ligados à subunidade $\alpha$ e $\beta$, respectivamente) e ligados em ponte por duas cisteínas (Cis $\alpha 88$ e Cis $\beta 95)$. Adicionalmente, existem dois ligandos não sulfurados: 0 azoto da ligação peptídica, pertencente à Cis $\alpha 88$ e o oxigénio da cadeia lateral da Ser $\beta 188$. No estado reduzido $\left(P_{N}\right)$ (figura $5 B$ ), a coordenação é efectuada apenas por seis cisteínas, três da subunidade $\alpha$ e três da subuni- figura 4 Representaçāo esquemática do heterotetrâmero, proteína de FeMo, da nitrogenase de Az. vinelandii. Os co-factores e o ião cálcio (a verde) estão representados por modelos "stick and ball" (Adaptado de Schmid et al., 2001).

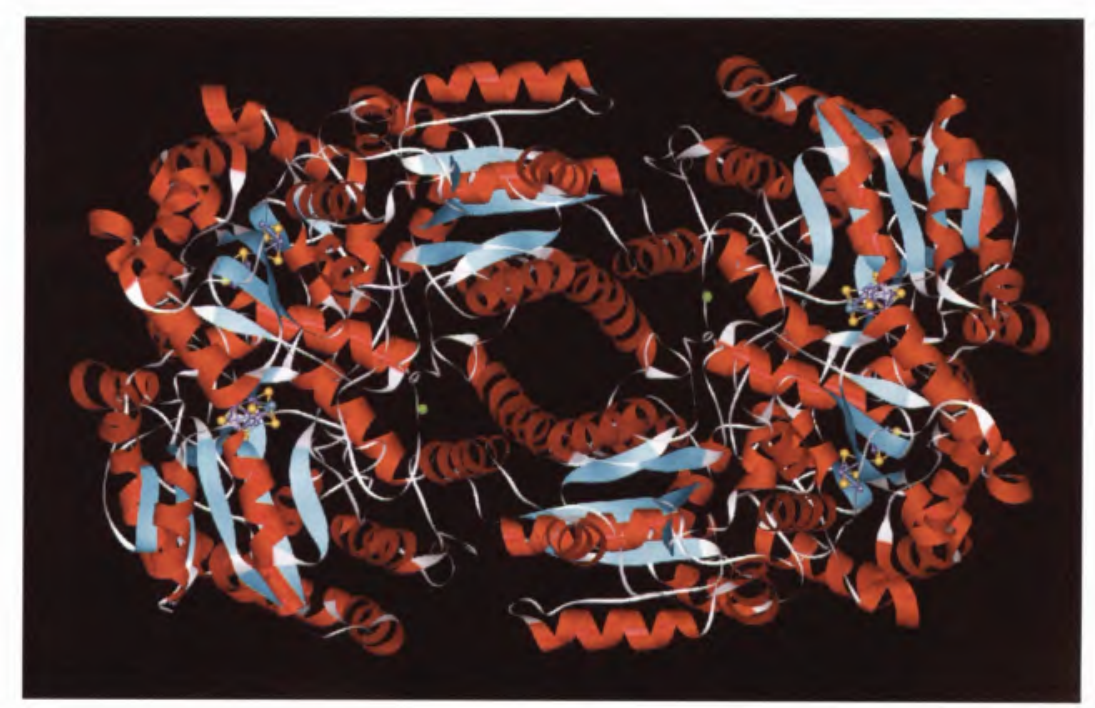



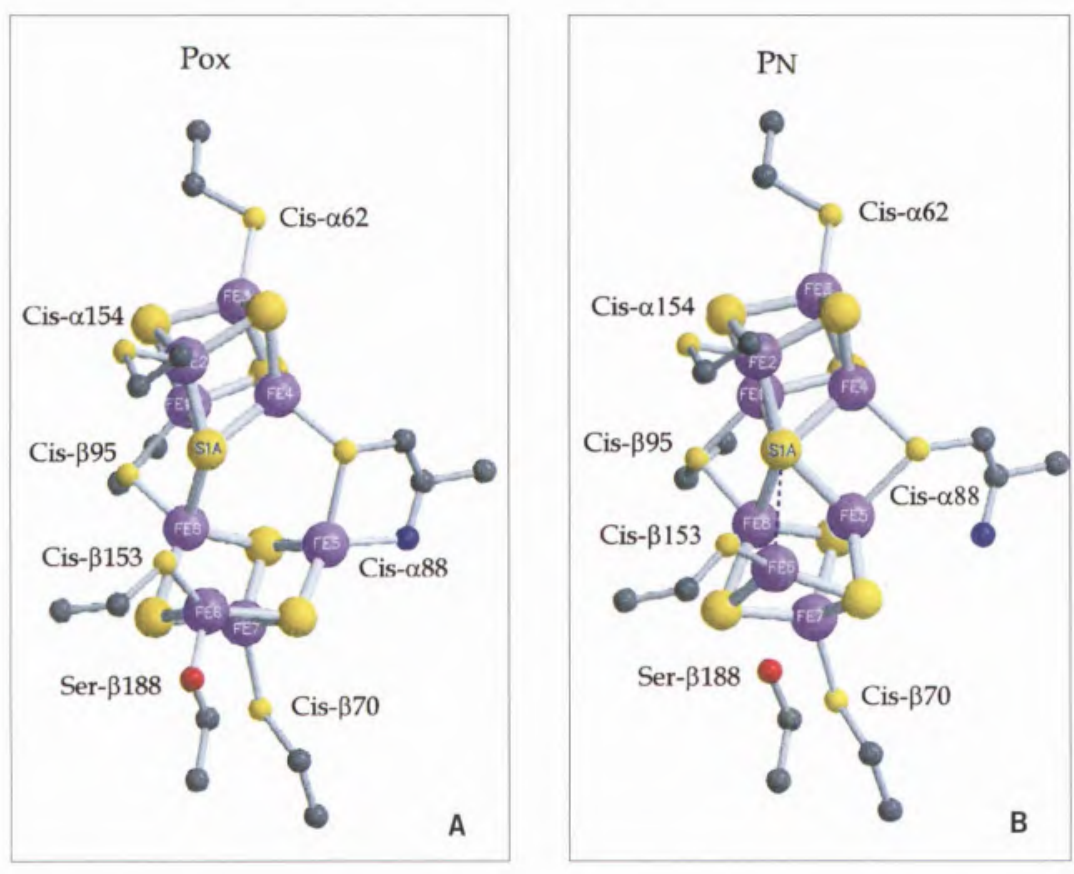

figura 5 Estrutura do agregado P e respectivos ligandos da proteina de FeMo da nitrogenase de Az. vinelandii, (A) no estado oxidado (Pox) e (B) no estado reduzido (PN) (Adaptado de Schmid et al., 2001).

dade $\beta$, (Cis $\alpha 62, \operatorname{Cis} \alpha 88, \operatorname{Cis} \alpha 154$, Cis $\beta 70$, Cis $\beta 95$ e Cis $\beta 153)$. A alteração da estrutura do agregado $P$, entre $P_{0 x}$ e $P_{N}$, é acompanhada por uma alteração dos ligandos, associada ao movimento do Fe5 e Fe6. O enxofre S1A (enxofre central) deixa de ter uma coordenação tetraédrica, para apresentar, no estado reduzido, uma coordenação octaédrica distorcida (Schmid et al., 2001).

0 co-factor de FeMo, a $10 \AA$ da superfície, está ligado essencialmente à subunidade a e pode ser considerado como derivado de um centro de [4Fe-3S] e de um agregado [Mo:3Fe:3S], cubanos parciais, ligados em ponte por três enxofres (figura 6). Apenas dois resíduos ligam o co-factor à cadeia polipeptídica (Cis 2.275 e His 4442 ), num arranjo tal que seis dos átomos de ferro possuem apenas três ligandos. A coordenação octaédrica do molibdénio é completada por ligação de um homocitrato (ligando bidentado) (Schmid et al., 2001).

Curiosamente, os ligandos dos agregado $\mathrm{P} \mathrm{e} \mathrm{co-factor} \mathrm{de} \mathrm{FeMo} \mathrm{pertencem} \mathrm{a} \mathrm{uma}$ mesma região, um centro composto por quatro folhas $\beta$ rodeadas por hélices $\alpha$, num arranjo estrutural semelhante ao observado na coordenação do agregado
$\mathrm{H}$ das hidrogenases contendo apenas ferro (Schmid et al., 2001).

\section{A proteína de Fe}

Cada uma das subunidades idênticas do dímero apresenta oito folhas $\beta$ torcidas, rodeadas por nove hélices $\alpha$ (figura 7); a parte central contém sete folhas $b$ paralelas e uma pequena folha $\beta$ antiparalela, num arranjo semelhante às proteínas de permuta de nucleotídeos. 0 centro de $[4 \mathrm{Fe}-4 \mathrm{~S}]$, localizado à superfície e na interface das duas cadeias polipeptídicas, está coordenado simetricamente por duas cisteínas, uma de cada subunidade (Cis97 e Cis132). Os dois locais de ligação da molécula de ATP (um em cada subunidade) distam cerca de $20 \AA$ do centro de ferro-enxofre (Ferguson, 1998; Schmid et al., 2001).

A estrutura cristalina obtida para o complexo, entre a proteína de $\mathrm{Fe}$, contendo $\mathrm{ADP} \mathrm{AlF}_{4^{-}}$(em ambos os locais de ligação do ATP) como factor de estabilização e a proteína de FeMo, permitiu confirmar o modo de associação entre as duas proteínas (a proteína de FeMo heterotetramérica possui dois homodíme-

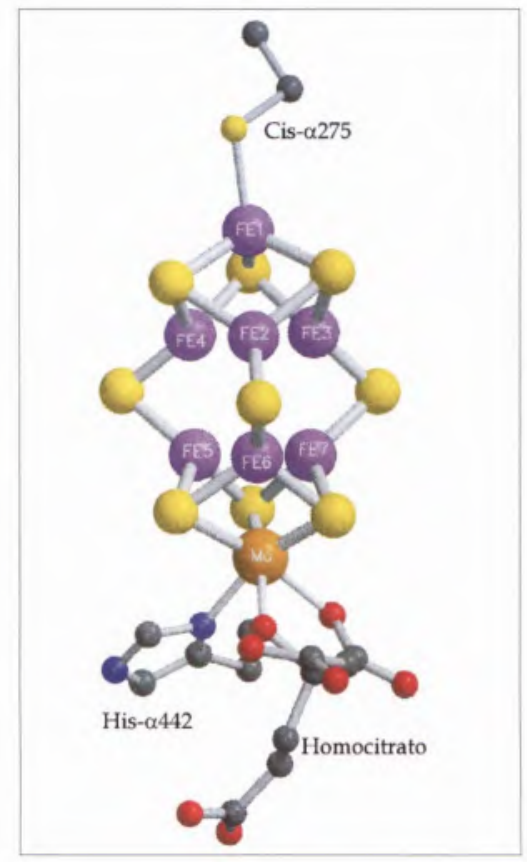

figura 6 Estrutura do agregado de FeMo e respectivos ligandos da proteina de FeMo da nitrogenase de Az. vinelandii (Adaptado de Schmid et al., 2001).

ros de proteína de Fe ligados) e tirar ilações relativamente ao mecanismo de catálise. A proteína de Fe sofre grandes alterações estruturais, que estão associadas à hidrólise do ATP, posicionando o centro de ferro-enxofre a $14 \AA$ do agregado $P$. Na proteína de FeMo apenas se observam alterações conformacionais no agregado $\mathrm{P}$, permanecendo inalterado o resto da molécula (Ferguson, 1998).

Deste modo, a redução do azoto molecular envolve inicialmente a formação dum complexo entre a proteína de $\mathrm{Fe}$ reduzida (por duas flavodoxinas), ligada a duas moléculas de ATP, e a proteína de FeMo. A subsequente transferência electrónica entre as duas proteínas, via agregado $\mathrm{P}$, está associada à hidrólise da ATP (duas moléculas por electrão transferido). Esta hidrólise impulsiona a dissociação do complexo formado pelas duas proteínas, favorece a estabilização da interface entre as subunidades na proteína de $\mathrm{Fe}$, contribuindo para o reposicionamento do centro de ferro-enxofre na superfície (para ser novamente reduzido) e permite nova ligação de duas moléculas de ATP. Na proteína de FeMo, as alterações observadas, entre o 


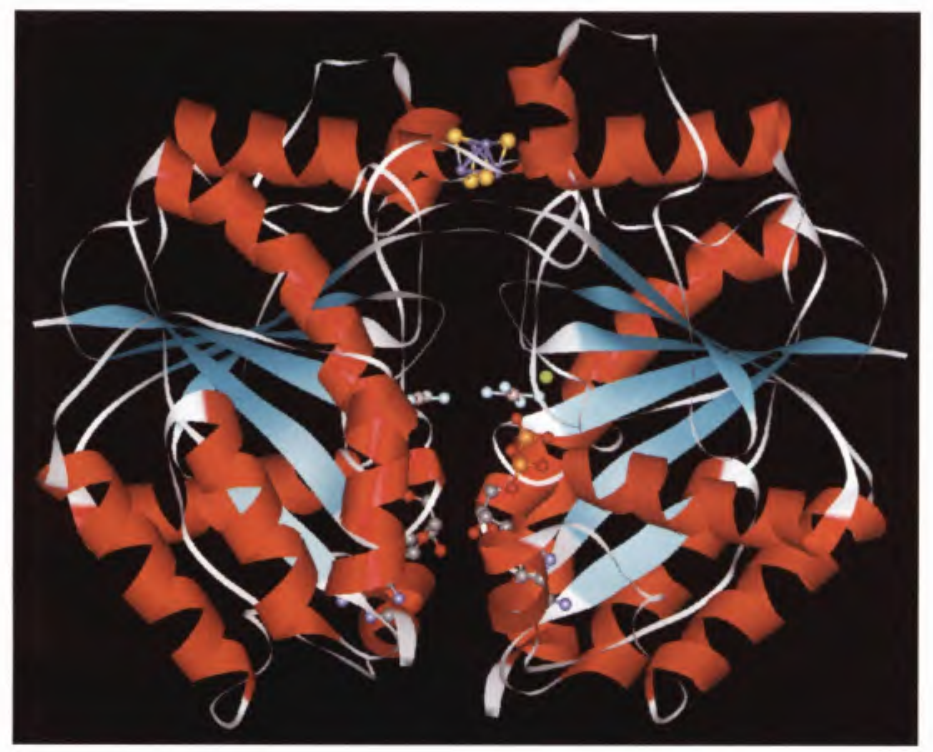

figura 7 Representação esquemática do homodímero, proteina de $\mathrm{Fe}$, da nitrogenase de $\mathrm{Az}$. vinelandii. O centro de [4Fe-4S] e os nucleotideos (ADP.AlF4-) estão representados por modelos "stick and ball" (Adaptado de Schmid et al., 2001).

estado oxidado e reduzido, apenas na coordenação do agregado $\mathrm{P}$, sugerem que a transferência de dois electrões está associada à entrada de dois protões; os ligandos libertados (a serina e a cisteína) podem ser protonados e os electrões são entregues ao sítio activo, o agregado FeMo, de uma forma sincronizada e mediada pelo agregado P. A reacção termina por repetição dos ciclos anteriores, até se terem acumulado electrões (ou protões) suficientes (Ferguson, 1998).

Geralmente é aceite que substratos e inibidores se ligam directamente aos centros metálicos; no entanto, a demonstração directa deste facto tem sido difícil e ainda não foi possivel, neste caso. Existem dois modos de ligação possiveis para o azoto molecular ao cofactor de FeMo: o $\mathrm{N}_{2}$ liga-se ao molibdénio e a um (ou vários) ferro(s), ou formam-se espécies híbridas. A ideia de uma transferência de dois electrões deve ser considerada com reservas, e ter apenas o estatuto de hipótese, pois algumas observações não são consistentes com este mecanismo (Ferguson, 1998).

\subsubsection{Mono-oxigenase da amónia (passo 2) - MOA}

A mono-oxigenase da amónia (MOA) é uma enzima membranar que catalisa a primeira reacção da nitrificação, de acordo com a seguinte equação:

$\mathrm{NH}_{3}+\mathrm{O}_{2}+2 \mathrm{H}^{+}+2 \mathrm{e}^{-} \rightarrow \mathrm{NH}_{2} \mathrm{OH}+\mathrm{H}_{2} \mathrm{O}$
O estudo da MOA tem sido dificultado, dada a labilidade da enzima. No entanto, a determinação de três genes estruturais permitiu estabelecer analogias com a mono-oxigenase do metano (MOM), também uma enzima membranar (McTavish et al., 1993; Holmes et al., 1995). O conhecimento da MOA será favorecido pelo estudo da MOM, recentemente purificada como uma enzima trimérica que liga até quinze átomos de cobre por complexo. Actualmente é aceite 0 facto de que a MOA liga um centro polinuclear de cobre e possivelmente ferro, mas como, até à data, muito pouco é conhecido acerca da MOM, o conhecimento da MOA é também limitado (Ferguson, 1998; Richardson e Watmough, 1999).

Independentemente da natureza molecular da MOA a sua actividade enzimática depende de uma fonte de electrões, possivelmente a reacçāo de oxidação da hidroxilamina a nitrito catalisada pela oxidase da hidroxilamina (passo 3); dos quatro electrões libertados dois são utilizados pela MOA na oxidação da amónia gerando outra molécula de hidroxilamina, os dois restantes são entregues a uma oxidase terminal da cadeia respiratória gerando um gradiente protónico e subsequente formação de ATP, ou são utilizados na redução do $\mathrm{NAD}^{+}$(Ferguson, 1998; Richardson e Watmough, 1999; Igarashi e Tanaka, 2001).

Paracoccus ( $\mathrm{Pa}$.) denitrificans, é um organismo desnitrificante, que pode efec- tuar alguns passos da nitrificação, sem deles depender para o seu crescimento, num processo denominado nitrificação heterotrófica. A MOA, recentemente isolada deste organismo, parece ser uma oxidase do quinol, que contém cobre coordenado a três histidinas, e difere da enzima de Nitrosomonas sp. (organismo autotrófico) pois consiste em apenas duas subunidades com massas moleculares de 38 e 46 kDa, respectivamente (Richardson et al., 1998).

\subsubsection{Oxidase da hidroxilamina (passo 3) - OHA}

A oxidase da hidroxilamina ( $\mathrm{OHA})$, uma enzima periplasmática, catalisa a oxidação da hidroxilamina a nitrito, de acordo com a seguinte equação:

$\mathrm{NH}_{2} \mathrm{OH}+\mathrm{H}_{2} \mathrm{O} \rightarrow \mathrm{NO}_{2}^{-}+5 \mathrm{H}^{+}+4 \mathrm{e}$

A OHA de Nitrosomonas (N.) europaea é um homotrímero de $200 \mathrm{kDa}$, que apresenta unicamente hemos como co-factor, covalentemente ligados, num total de vinte e quatro (sete hemos $c$ e um hemo $\mathrm{P}_{460}$ por subunidade). Os hemos estāo dispostos em cada subunidade como um agregado triplo, dois agregados duplos e um hemo magneticamente isolado. Enquanto os hemos c estão envolvidos na transferência electrónica intra e intermolecular, o hemo $\mathrm{P}_{460}$ (localizado na parte superior de uma cavidade), pentacoordenado, é o sítio activo permitindo deste modo a ligação do substrato, a hidroxilamina $\left(\mathrm{NH}_{2} \mathrm{OH}\right)$. De todos os hemos, apenas o hemo $\mathrm{P}_{460}$ e 0 
figura 8 Representação esquemática de uma subunidade da oxidase da hidroxilamina de N. europaea. Os hemos são apresentados por módelos "stick and ball" (Adaptado de Igarashi e Tanaka, 2001)

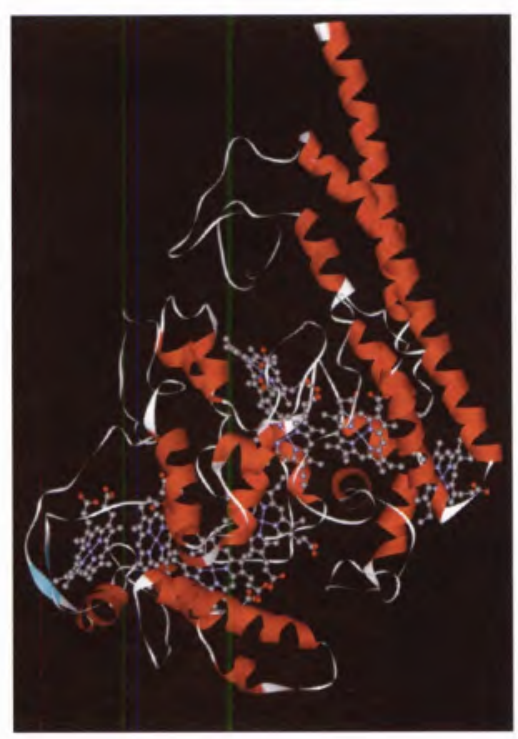

hemo 1 estão parcialmente expostos ao solvente, pelo que funcionam como ponto de entrada e saída dos electrões, respectivamente. $\mathrm{O}$ agregado triplo está envolvido na rápida transferência electrónica, do substrato para o aceitador (o citocromo $\mathrm{C}_{554}$, um citocromo tetrahémico) de modo a evitar a formação de óxido nítrico ou óxido nitroso (Ferguson, 1998; Richardson e Watmough, 1999; Igarashi e Tanaka, 2001).

Os hemos $\mathrm{c}$ apresentam uma coordenação bis histidina e o hemo $\mathrm{P}_{460}$ (assim denominado por apresentar uma absorção característica na sua forma reduzida), pentacoordenado, possui uma ligação covalente adicional a um resíduo de tirosina (Tir467) duma subunidade adjacente (entre um carbono meso do hemo e um carbono benzílico da tirosina) que parece ser responsável pela trimeriza- ção da molécula (Igarashi e Tanaka, 2001).

\section{Estrutura global}

A molécula é bastante compacta, em resultado de uma vasta área de contacto entre as subunidades, mas possui uma grande cavidade na parte inferior e fendas entre as subunidades (com capacidade para albergar uma molécula de grandes dimensões como é o citocromo $\mathrm{C}_{554}$ ). No topo do trímero, seis longas hélices e três pares de hélices torcidas, das três subunidades, formam um pilar no centro da molécula, estabilizado por contactos hidrofóbicos entre dois discos de tríades de leucinas. Cada subunidade, com uma topologia essencialmente em hélice a, está organizada em dois domínios, para além do C-terminal flexível (figura 8). O domínio do $\mathrm{N}$-terminal contém duas folhas $\beta$ curtas e 14 hélices $\alpha$, com cinco hemos $c$ e um hemo $\mathrm{P}_{460}$. Quatro dos hemos (hemos 1 a 3 e 5) estão protegidos pela cadeia polipeptídica e o seu acesso ao solvente é limitado por duas áreas de pequenas dimensões. O domínio central contém dois hemos $c$ (hemos 7 e 8) e dez hélices $a$, incluindo as longas hélices que formam o pilar central. 0 hemo magneticamente isolado (hemo 8) está localizado no final do feixe de hélices a do domínio central e o agregado triplo (hemos 6 e 7 e $P_{460}$ ) está localizado num bolso entre o $\mathrm{N}$-terminal e o domínio central (Igarashi e Tanaka, 2001).

\section{Os hemos}

Os hemos, localizados na metade inferior da molécula, formam quatro grupos (figura 9). Estes estão muito próximos e interactuam directamente, formando uma rede possivelmente envolvida na transferência electrónica (Igarashi e Tanaka, 2001).

No primeiro grupo (a amarelo), o agregado triplo é composto pelos hemos 6,7 e $\mathrm{P}_{460}$, num arranjo praticamente coplanar; no entanto, a interacção entre o hemo $P_{460}$ e o hemo 6 é ligeiramente diferente da existente entre os hemos $6 \mathrm{e}$ 7, pelo facto do hemo $\mathrm{P}_{450}$ apresentar uma rotação tal que os seus grupos propionato formam ligações por pontes de hidrogénio com os mesmos grupos do hemo 6 , tornando, deste modo, acessível a posição de coordenação no hemo $P_{460}$. O segundo grupo (a azul), o agregado duplo I, é composto pelos hemos 3 e 5 que, à semelhança dos hemos 6 e 7 ,

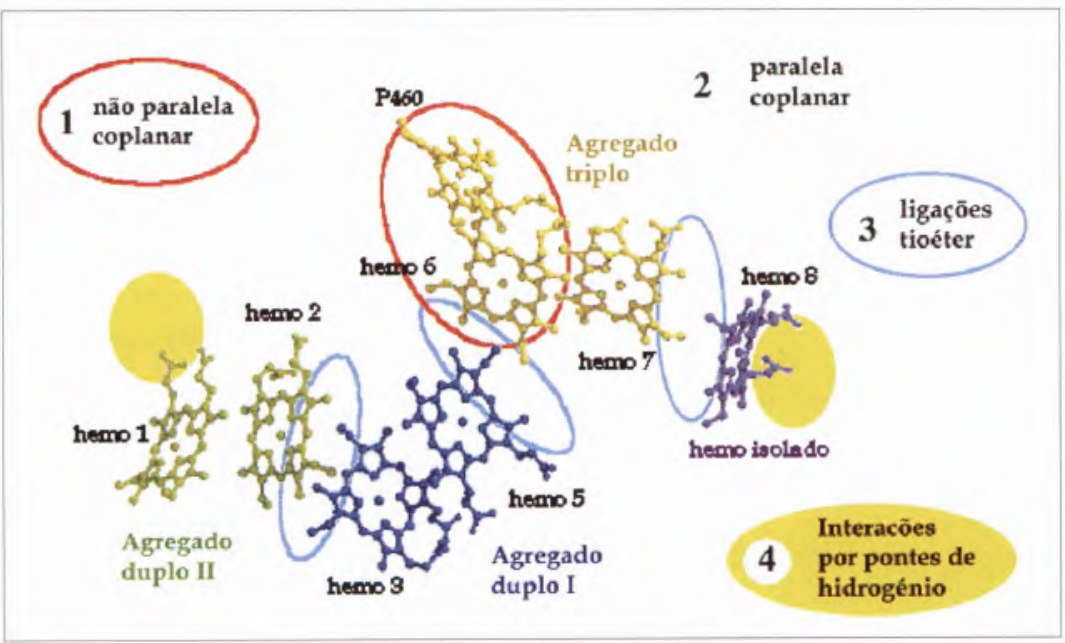

figura 9 Estrutura dos hemos, disposiçãc espacial e tipos de interaç̧ão hemo-hemo da oxidase da hidroxilamina de N. europaea. As interacções são representadas por uma elipse de cor diferente (agregado triplo (amarelo), agregado duplo I (azul), agregado duplo II (verde), hemo isolado (lilás) (Adaptado de Igarashi e Tanaka, 2001). 
são praticamente coplanares. Os grupos propionato, de ambos os hemos, estão direccionados para a cavidade central inferior e dois deles expostos ao solvente. Da mesma forma que os hemos 6 e $P_{460}$, o hemo 3 interactua com o hemo 5 que, por sua vez, interactua com o hemo 6 do agregado triplo. 0 arranjo do terceiro grupo (a verde), o agregado duplo II (hemos 1 e 2), é semelhante ao dos hemos 3 e 5 no agregado duplo I e dos hemos 6 e 7 no agregado triplo (os hemos são praticamente paralelos, mas ligeiramente inclinados em cerca de $20^{\circ}$ ). Os seus grupos propionato estão orientados para a parte superior da molécula; um dos grupos do hemo 1 está em contacto com o solvente e existem interacçōes por pontes de hidrogénio com resíduos da subunidade adjacente, contribuindo, deste modo, para a formação do trímero. Adicionalmente, o hemo 2 interactua com o hemo 3 do agregado duplo I. O quarto grupo, o hemo isolado (hemo 8, a lilás), estabelece interacções com o agregado triplo e com o agregado duplo II da subunidade adjacente (Igarashi e Tanaka, 2001).

A oxidação da hidroxilamina decorre em dois passos: a desidrogenação da hidroxilamina, seguida da oxigenação do intermediário azotado (espécie ferroso-nitrosilo) para formar nitrito, não havendo libertação de intermediários. No entanto, dada a inexistência de uma estrutura derivada, o mecanismo de oxidaçăo da hidroxilamina está ainda por elucidar. A estrutura do hemo $P_{460}$ e 0 arranjo dos restantes hemos permitem uma transferência electrónica concertada de dois electrōes. Quando o hemo $P_{460}$ extrai dois electrōes à hidroxilamina, é promovida a transferência para o aceitador (hemos 6 e 7). Estes hemos estão acoplados e interactuam com o hemo $P_{460}$, removendo os dois electrões, disponibilizando-o para o segundo passo. A proximidade entre os agregados permite a transferência entre estes e os agregados duplos (hemos 3 e 5 e hemos 1 e 2) e daqui para 0 aceitador final, o citocromo $C_{554}$. A existência de agregados dihémicos coplanares reforça a ideia de uma transferência di-electrónica, ou a transferência electrónica pode envolver a saída de apenas um electrão, via agre- gado II, para o citocromo $C_{554}$, convertendo um sistema de quatro electrões (a $\mathrm{OHA}$ ) num sistema monoelectrónico compativel com o citocromo $C_{552}$, associado com as oxidases terminais. 0 hemo 8 , que interactua com o agregado Il da subunidade adjacente, pode funcionar como um caminho distinto, transferindo um electrão para um dos hemos do agregado duplo adjacente (Ferguson, 1998; Richardson e Watmough, 1999).

No ciclo catalítico, e por analogia com a redutase do nitrito multihémica, $\mathrm{ccNiR}$ (passo 6), parece ser importante a participação dum aspartato (Asp267), que funciona como aceitador de protões na oxidação da hidroxilamina, duma histidina (His268), provavelmente envolvida no processo de mono-oxigenação, e duma tirosina (Tir334), que funciona como um estabilizador do estado intermediário (Ferguson, 1998).

Contrariamente à OHA multihémica de organismos autotróficos (a de N. europaea descrita anteriormente), a OHA envolvida na oxidação heterotrófica da amónia (como por exemplo de Pa. denitrificans) é uma enzima monomérica de $18 \mathrm{kDa}$ (periplasmática), que liga ferro não hémico; possivelmente um centro dinuclear de ferro, como centro catalíti$\mathrm{co}$, e um centro mononuclear envolvido na transferência electrónica. A catálise envolve a formação de nitrito e de óxido nitroso, em condições aeróbias, enquanto que em condições anaeróbias apenas se forma óxido nitroso, num mecanismo que envolve apenas transferência de dois electrões (Richardson et al., 1998; Igarashi eTanaka, 2001).

A necessidade da OHA de N. europaea realizar uma oxidação que envolve quatro electrões, enquanto que a OHA de $\mathrm{Pa}$. denitrificans executa uma oxidação que envolve dois electrões, é presumivelmente a razão da grande complexidade da enzima de $N$. europaea, comparativamente com a $\mathrm{OHA}$ de $\mathrm{Pa}$. denitrificans (Richardson et al., 1998).

\subsubsection{Oxidase do nitrito (passo 4)}

O passo oxidativo de nitrito a nitrato é catalisado pela oxidase do nitrito, de acordo com a equação:
$\mathrm{NO}_{2}^{-}+\mathrm{H}_{2} \mathrm{O} \rightarrow \mathrm{NO}_{3}{ }^{-}+2 \mathrm{H}^{+}+2 \mathrm{e}-$

A análise da sua sequência de aminoácidos indica que esta enzima membranar é análoga à redutase do nitrato membranar, NAR, relativamente às subunidades a e b. A primeira, a subunidade catalítica, contém o co-factor de molibdénio, uma molibdopterina guanosina dinucleotídeo (MGD) e a segunda contém centros de ferro-enxofre. Mecanisticamente, a oxidação do nitrito parece ser o inverso da redução do nitrato (Ferguson, 1998)

\subsubsection{Redutase do nitrato (passo 5 ) - NAP, NAR, NAS}

A redutase do nitrato catalisa a redução do nitrato a nitrito, de acordo com a seguinte equação:

$\mathrm{NO}_{3}^{+}+2 \mathrm{H}^{+}+2 \mathrm{e}-\rightarrow \mathrm{NO}_{2}^{-}+\mathrm{H}_{2} \mathrm{O}$

Os procariotas possuem três subclasses, estruturalmente distintas de redutases do nitrato: as assimilativas citoplasmáticas (NAS), as dissimilativas membranares (NAR) e as dissimilativas periplasmáticas (NAP), que possuem um co-factor de molibdénio no seu sítio activo, uma variante da molibdopterina mononucleotídeo (MPT), uma molibdopterina guanosina dinucleotídeo (MGD) (Richardson e Watmough, 1999; Romão et al., 2001).

A única estrutura de cristelográfica conhecida até à data é a da redutase do nitrato periplasmática (NAP) de Desulfovibrio (D.) desulfuricans ATCC 27774 (Dias et al., 1999 a; 1999 b). Contrariamente a outras enzimas homólogas, em que a subunidade catalítica (NapA) está associada a outras subunidades menores, a NAP possui uma única subunidade, tornando-se no membro mais simples das enzimas englobadas na classe da redutase do dimetilo sulfóxido (DMSOR) (Moura et al., 1997; Romão et al., 1997). A NAP possui um centro de [4Fe-4S] e um co-factor de molibdénio bis-MGD; o centro de ferro-enxofre participa na transferência electrónica a partir dum doador fisiológico, ainda desconhecido, para o centro de molibdénio onde decorre a catálise, a redução do nitrato a nitrito (Bursakov et al., 1995; Carneiro et al., 1995; Moura et al., 
figura 10 Representação esquemática da NAP de D. desulfuricans ATCC 27774. Os cofactores estāo representados por modelos "stick and ball" (Adaptado de Romão et al., 2001)

2001). A proximidade dos dois co-factores, bem como a existência de interacções entre ligações facilita a transferência intramolecular com participação de uma lisina (Lis49). Uma arginina (Arg354) participa na estabilização do substrato (o nitrato) durante o ciclo catalítico (Dias et al., 1999 b).

A NAP (figura 10) tem uma forma elipsoidal coincindindo a menor dimensão com a direcção da cavidade que conduz ao sítio activo. Com uma topologia $\alpha / \beta$ organizada em quatro domínios é semeIhante à desidrogenase do formato (FDHh) de Escherichia (E.) coli (Sun et al., 2001). O centro de [4Fe-4S] está localizado na periferia da molécula, no

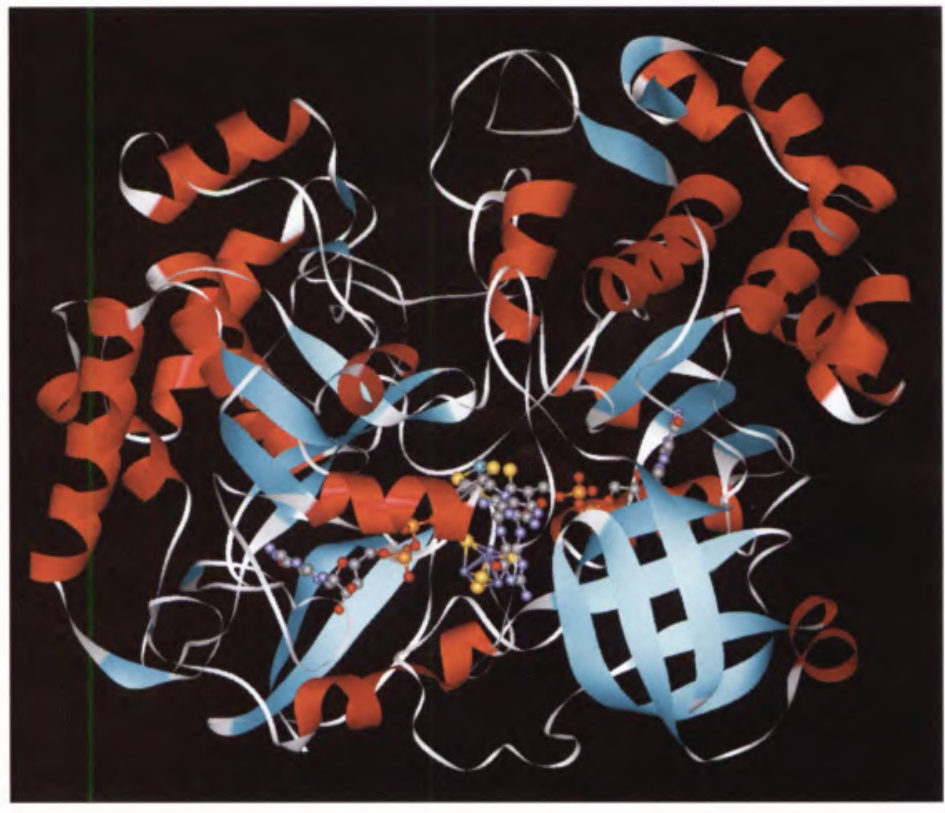

domínio I, enquanto que o co-factor de molibdénio se estende no interior da molécula, interactuando com resíduos de todos os domínios (Romão et al., 2001).

O arranjo espacial da NAP (incluindo o modo como o molibdénio coordena as duas MGD) define um eixo de simetria, relativamente aos domínios II e III, criando uma cavidade em forma de funil, revestida com resíduos carregados, e que permite o acesso ao centro de molibdénio. $\mathrm{O}$ co-factor (localizado a $15 \AA$ A da superfície) estende-se no interior da molécula por uma distância máxima de 32 Å e é estabilizado por ligações por pontes de hidrogénio e uma ligação adicional a um resíduo da cadeia polipeptídica (Cis140). No estado oxidado, o molibdénio possui uma geometria trigonal prismática distorcida, em que quatro dos ligandos são os ditiolenos das duas pterinas (MGD 811 e 812), o quinto é a Cis140 e o sexto um hidroxo/água, que aponta no sentido da cavidade e que dá lugar, no estado reduzido, ao substrato, o nitrato. O molibdénio dista $12 \AA$ de um dos átomos de ferro do centro de ferro-enxofre e, à semelhança de outras molibdoenzimas, é possível definir um percurso electrónico através das ligações (via MGD 812) entre os dois co-factores, envolvendo a participação de uma molécula de água ou, alternativamente, um resíduo de lisina (Lis49) figura 11 Estrutura e disposição do centro de ferro-enxofre e do co-factor de molibdénio bis. MGD da NAP de D. desulfuricans ATCC 27774. O percurso electrónico proposto é mediado por uma molécula de água ou pela Lis49 (Adaptado de Romão et al., 2001).

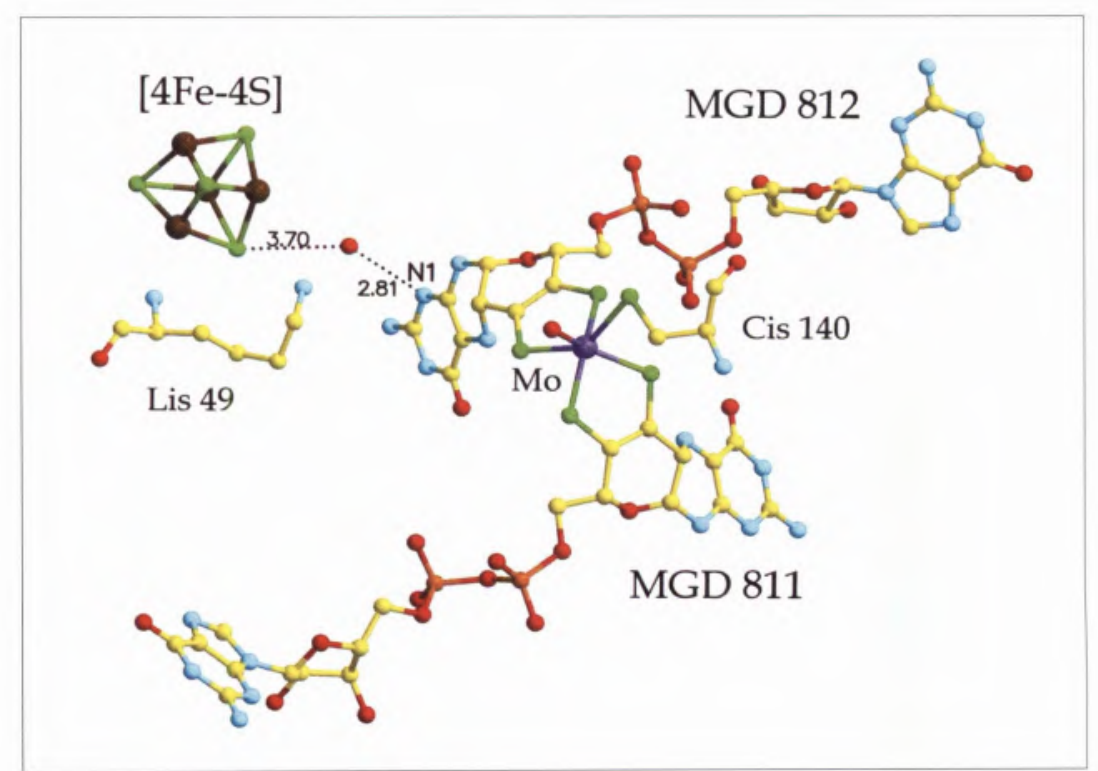




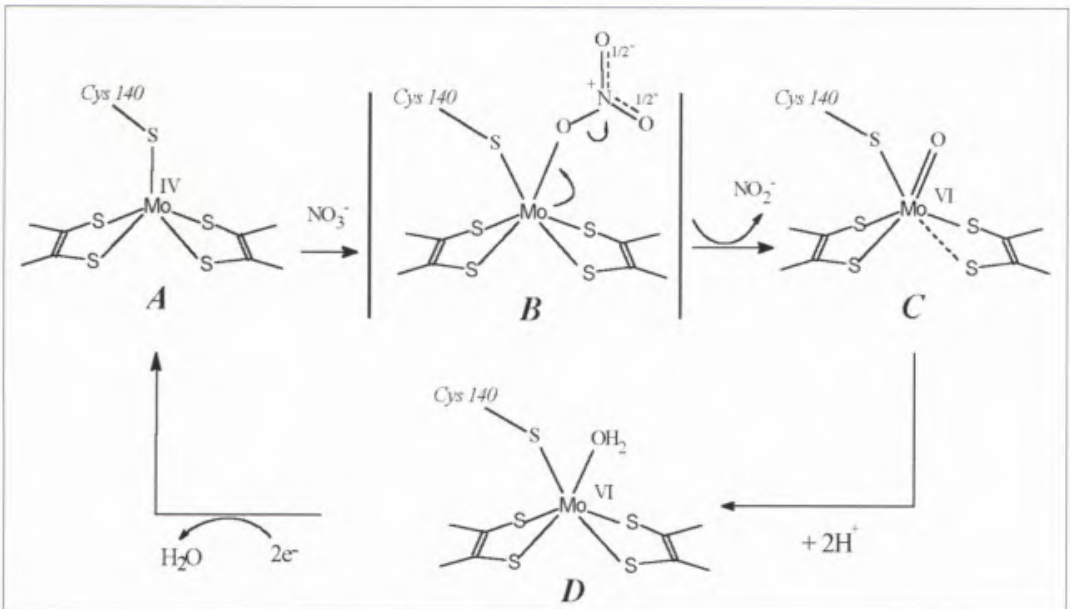

(figura 11) (Dias et al., 1999 b; Romão et al., 2001).

0 mecanismo de catálise proposto (figura 12) baseia-se em estudos com compostos modelo ou enzimas relacionadas. A reacção tem início com a forma reduzida (MolV) que pode ligar o nitrato; a ligação N-O é enfraquecida, facilitando a libertação do produto, o nitrito; 0 molibdénio é então oxidado (a MoVI), apresentando uma ligação oxo a um oxigénio do nitrato. Segue-se a transferência de dois protões, possivelmente a partir de moléculas de água existentes no sítio activo; a transferência de dois electrões, a partir do centro de ferro-enxofre, com concomitante saída de uma molécula de água origina a forma nativa (MolV). Presume-se que alguns dos resíduos carregados, existentes na cavidade catalítica, estão implicados no ciclo catalítico; a Arg354 ou a Arg138 são potenciais estabilizadores do nitrato (Dias et al., 1999 b; Romão et al., 2001).

\subsubsection{Redutase do nitrito (passo 6)}

A redução do nitrito a óxido nítrico, de acordo com a seguinte equação:

$\mathrm{NO}_{2}+2 \mathrm{H}^{+}+\mathrm{e}-\rightarrow \mathrm{NO}+\mathrm{H}_{2} \mathrm{O}$

é catalisada por dois tipos de redutases do nitrito periplasmáticas, dependendo do co-factor presente: uma enzima hémica, um citocromo $\mathrm{Cd}_{1}$ (NiR), ou uma proteína de cobre, a CuNiR. Os diferentes co-factores permitem uma fácil distinção bioquímica (Averill, 1996). No entanto, existem redutases do nitrito multihémicas, contendo, como co-factores, apenas hemos c (ccNiR) capazes de reduzir o nitrito a amónia, utilizando electrões da oxidação do formato ou do hidrogénio, de acordo com a seguinte equação:

$\mathrm{NO}_{2}{ }^{+}+8 \mathrm{H}^{+}+6 \mathrm{e}-\rightarrow \mathrm{NH}_{4}^{+}+2 \mathrm{H}_{2} \mathrm{O}$

A ccNiR catalisa também a redução do óxido nítrico e da hidroxilamina a amónia, bem como a redução do sulfito a sulfureto (Einsle, 2001). figura 12. Mecanismo de catálise da NAP de D. desulfuricans ATCC 27774 (Adaptado de Romão et al., 2001).

\section{Redutase do nitrito do tipo $\mathrm{cd}_{1}(\mathrm{NiR})$}

As estruturas da NiR, disponíveis para Pseudomonas (Ps.) aeruginosa e $\mathrm{Pa}$. denitrificans GB17, apesar de apresentarem um arranjo global semelhante, diferem no ambiente de ligação dos hemos, tanto para o estado oxidado, como para o estado reduzido. A NiR é um homodímero (2x60 kDa); cada monómero possui um hemo c, covalentemente ligado à cadeia polipeptídica, por ligaçōes tioéter (Cis65 e Cis68), e um hemo $d_{1}$ ligado de um modo não covalente. Distam, numa mesma subunidade, de $11 \AA$ num arranjo espacial tal que o ângulo entre eles é de $60^{\circ}$. 0 hemo $c$ funciona como aceitador de electrões, provenientes dum citocromo c externo ou de uma cupredoxina, e o hemo $d_{1}$ constitui o sítio activo da enzima. Duas histidinas participam na catálise, e tanto o substrato como o produto (nitrito e óxido nítrico (NO), respectivamente, são estabilizados por várias ligações por pontes de hidrogénio (Averill,

figura 13 Representaçāo esquemática da NiR de Pa. denitrificans GB17 (Pa. pantotrophus) (b) vista do domínio de ligação do hemo d1 (90 relativamente a (a)). Os hemos estão representados por modelos "stick and ball" (Adaptado de Allen et al., 2001).
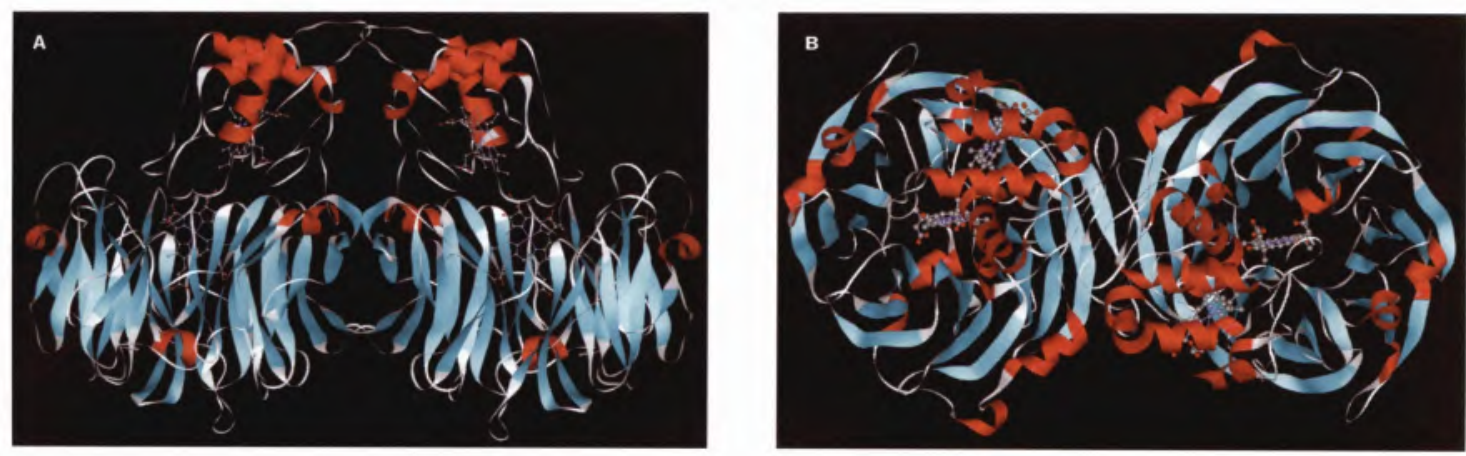
figura 14 Representação dos hemos e respectivos ligandos da NiR de $\mathrm{Pa}$. denitrificans GB17. Duas histidinas (a verde) estão possivelmente envolvidas na catálise (Adaptado de Allen et al., 2001).
1996; Allen et al., 2001; Moura e Moura, 2001).

Cada subunidade está organizada em dois dominios estruturalmente diferentes (figura 13A). 0 ambiente de coordenação do hemo c é essencialmente hidrofóbico, de modo que este expõe os seus grupos propionato ao solvente. 0 hemo $d_{1}$, localizado num túnel definido pela hélice de folha $\beta$ (figura 13B), estabelece inúmeros contactos com a cadeia polipeptídica e com moléculas de água localizadas no interior. A associação das duas subunidades deve-se à existência de ligações de hidrogénio entre os domínios em hélice de folha $\beta$ dos dois monómeros (Allen et al., 2001).

O domínio $\mathrm{N}$-terminal, essencialmente em hélice $\alpha$, contém o hemo c e o C-terminal com uma topologia em " $\beta$-propeler"; uma hélice de oito lâminas em folha $\beta$ (cada lâmina é composta por quatro folhas $\beta$ antiparalelas) liga o hemo $d 1$.

Em Pa. denitrificans GB17, o hemo c apresenta uma coordenação bis-histidina (His17 e His69) e o hemo dl, também hexa coordenado, possui, como ligandos, uma uma tirosina, do domínio do hemo $c$ e uma histidina (Tir25 e His200) (figura 14). No entanto, após redução, ambos os hemos alteram a sua coordenação: no hemo c uma histidina é substituída por uma metionina e o

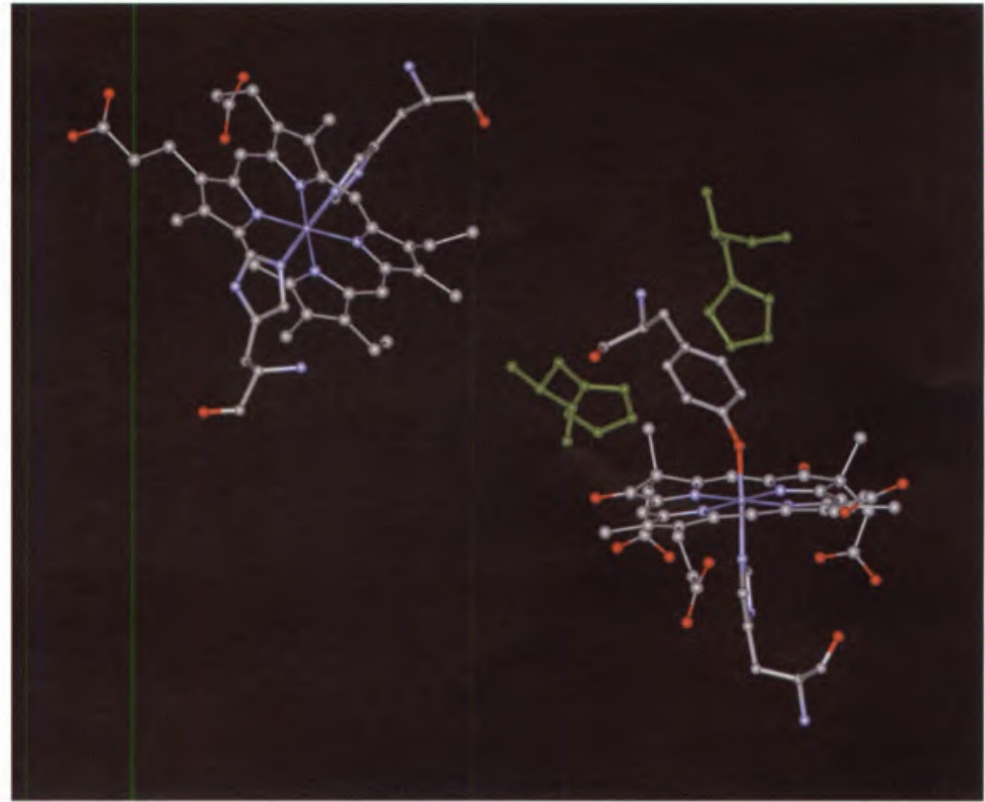

hemo $d_{1}$, agora pentacoordenado, mantém a histidina, mas "perde" a tirosina (Allen et al., 2001).

Por sua vez em Pseudomonas (Ps.) aeruginosa, o hemo $c$ apresenta, no estado oxidado, uma coordenação metionina-histidina (Met88 e His51), típica de citocromos $c$ e o hemo $d_{1}$ tem como ligandos, uma histidina (His182) e um hidroxilo. Este último estabelece uma ligação, por ponte de hidrogénio, com uma tirosina (Tir10) pertencente à outra subunidade formando, deste modo, uma ligação cruzada na região do $\mathrm{N}$-terminal. No estado reduzido, o hemo c mantém a coordenação e a tirosina (Tir10) do hemo $d_{1}$, apesar de conservada, não é equivalente à Tir25 de $\mathrm{Pa}$. denitrificans GB17, isto é não participa na catálise; a sua substituição por fenilalanina não altera as propriedades catalíticas (Cutruzzolà et al., 1997; Allen et al., 2001).

A catálise (figura 15) é iniciada com a ligação do nitrito, através do seu átomo de azoto, ao hemo $d_{1}$ reduzido. A posterior redução e desidratação do nitrito resulta na formação de um intermediário nitrosilo $\left(\mathrm{Fe}^{2+}-\mathrm{NO}^{+}\right.$ou $\left.\mathrm{Fe}^{3+}-\mathrm{NO}\right)$. Duas histidinas (His345 e His388, em Pa. denitrificans GB17 e His327 e His369, em Ps. aeruginosa) participam na reacção de protonação acoplada à remoção de um dos oxigénios (como água) do nitrito.
O passo crítico é a dissociação do óxido nítrico; o intermediário nitrosilo ganha um electrão, por transferência intraelectrónica do hemo c, conduzindo à inactivação da enzima por formação de um complexo estável $\left(\mathrm{Fe}_{2+}-\mathrm{NO}\right)$. Contudo, a forma de evitar a sua formação não está ainda estabelecida in vivo (Averill, 1996; Ferguson, 1998, Allen et al., 2001; Cutruzzolà et al., 2001). Em Pa. denitrificans GB17, a Tir25 parece estar envolvida na libertação do NO, provavelmente coordenando-se de novo ao hemo $d_{1}$ durante cada ciclo catalítico. O hemo $c$ parece ter um papel no controlo da velocidade de transferência intraelectrónica entre os hemos $c$ e $d 1$ evitando a inibição da NiR pelo produto; deste modo, o hemo $d 1$ só deve ser novamente reduzido após libertação do NO (Berks et al., 1995, Allen et al., 2001; Lopes et al., 2001; Moura e Moura, 2001).

O mecanismo proposto, não é no entanto universal, na medida em que o resíduo de tirosina (Tir25) não é encontrado em PS. stutzeri e a tirosina (Tir10) de Ps. aeruginosa não é essencial para a catálise (Cutruzzolà et al., 1997; Allen et al., 2001).

\section{Redutase do nitrito contendo cobre (CuNiR)}

A CuNiR de Achromobacter (Ach.) cycloclastes (figura 16) é um homotrí- 


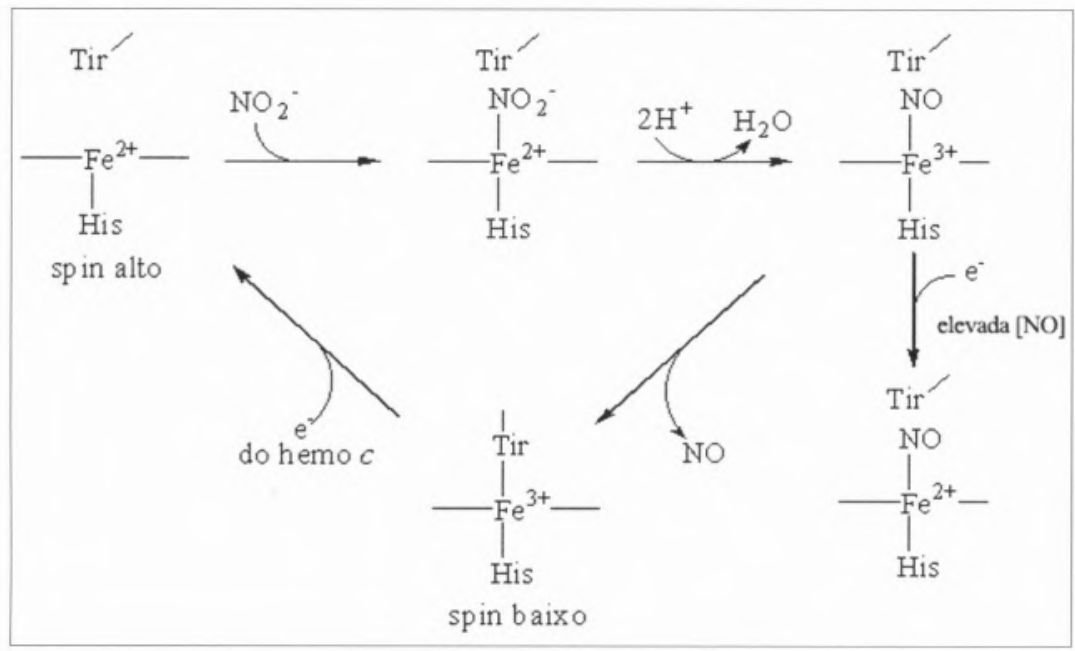

mero $(3 \times 37 \mathrm{kDa})$ contendo dois cobres por monómero (não existem outros cofactores) que distam 12,6 $\AA$. O cobre do tipo 1 , localizado no $\mathrm{N}$-terminal, funciona como doador electrónico, enquanto que o cobre do tipo 2, ligado na interface dos monómeros, é o sítio catalítico. Dois resíduos não coordenados ao cobre (Asp98 e His255) funcionam como doadores de protões durante o ciclo catalítico (Adman e Murphy, 2001).

Cada monómero, essencialmente em folha $\beta$, possui dois domínios, iguais em tamanho, com uma topologia em "Greek-key", característico das cupredoxinas. O domínio $\mathrm{N}$-terminal de cada monómero interactua com o domínio $\mathrm{C}$ terminal do monómero adjacente; o pri- meiro forma o canto do trímero, enquanto que o $\mathrm{C}$-terminal se encontra no centro. Uma cauda proeminente no Cterminal é essencial para a manutenção da estrutura quaternária (Adman e Murphy, 2001; Moura e Moura, 2001).

Duas histidinas, uma cisteína e uma metionina (His95, Cis136, His145 e Met150), numa geometria tetraédrica distorcida (ou triangular plana distorcida, considerando que a metionina é o ligando mais fracamente ligado), completam a esfera de coordenação do cobre do tipo 1 . O cobre do tipo 2 está coordenado a três histidinas, duas de um monómero (His100 e His135) e a terceira do monómero adjacente (His306); apresenta uma geometria tetraédrica e, na ausência de substrato, possui a figura 15 Mecanismo de catálise da NiR de $\mathrm{Pa}$. denitrificans GB17 (Adaptado de Berks et al., 1995; Ferguson, 1998).

quarta posição de coordenação ocupada por uma molécula de água (ou hidroxilo). O cobre do tipo 2 localiza-se na parte inferior de uma cavidade (a $12 \AA$ da superfície) que alberga dois resíduos carregados (Asp98 e His255), mas é hidrofóbica de um dos lados; o canal que conduz à superfície está preenchido com moléculas de água, mas a parte hidrofóbica que contém a His255, favorece a saída do produto, o óxido nítrico (NO). Interacções de hidrogénio específicas mantêm a orientação dos ligandos de cobre (figura 17) (Adman e Murphy, 2001).

Durante a catálise (figura 18) o nitrito liga-se assimetricamente à forma oxidada, deslocando o hidroxilo (ou o cloreto, no caso da CuNiR de A. xylosoxidans).

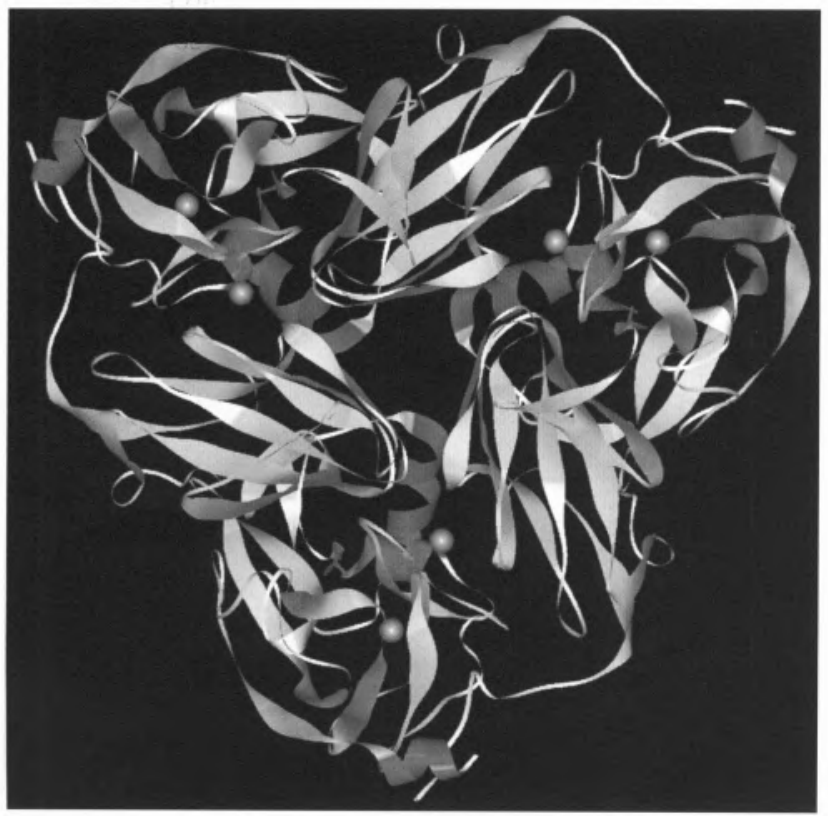

figura 16 Representação esquemática da CuNiR de Ach. cycloclastes. Os cobres (a laranja) estão representados por modelos "stick and ball" (Adaptado de Adman e Murphy, 2001). 
figura 17 Representação dos cobres (a amarelo claro) e respectivos ligandos da CuNiR de Ach. cyclosclastes. Os resíduos Asp 98 e His 225 (a verde) funcionam como doadores de protões durante o ciclo catalítico (Adaptado de Adman e Murphy, 2001).

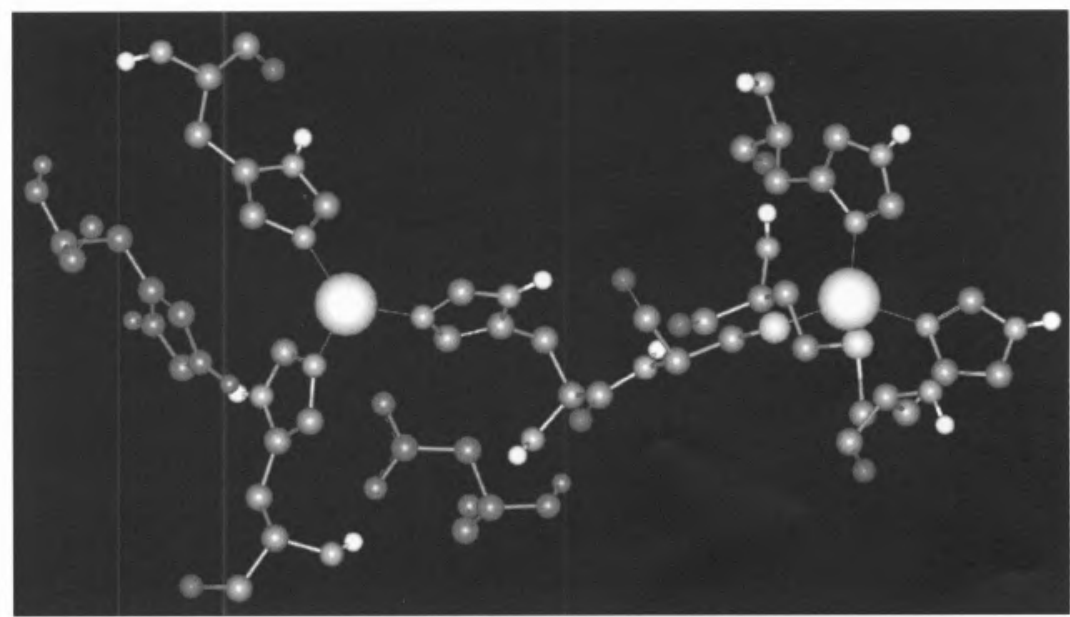

que distam entre si de 9,3 a 12,7 A. Um ião cálcio, localizado na proximidade do sítio activo, desempenha um papel estrutural fundamental na organização do mesmo, assegurando a orientação dos resíduos "activos". Alguns destes resíduos carregados funcionam como doadores de protões durante o ciclo catalítico (Einsle, 2001).

A ccNiR é um dímero com predominância em hélice $\alpha$, em que as três mais longas hélices de cada monómero formam a parte central; existem apenas duas folhas b, antiparalelas, na parte periférica da molécula. Cada monómero possui apenas um domínio compacto que envolve os cinco hemos, localizados relativamente próximos e na parte inferior da molécula. 0 sítio activo, hemo 1 . situa-se na parte inferior de uma cavidade em forma de funil, definida a partir da superfície e que alberga resíduos carregados que estabelecem interac- ções com o substrato ligado (Arg113, His282, Tir217). O ião cálcio está coordenado por um glutamato, de um modo bidentado, uma glutamina, dois oxigéduas moléculas de água; liga dois segmentos da proteína que contêm os resíduos envolvidos na catálise, assegurando a sua orientação adequada (Einsle, 2001).

Todos os hemos, com excepção do hemo 1 , onde decorre a catálise, possuem uma coordenação bis-histidina. 0 hemo 1 é pentacoordenado e apresenta uma coordenação pouco vulgar, uma lisina (Lis133) em vez da usual histidina. 0 hemo 3 apresenta um empilhamento paralelo com os hemos mais próximos, hemos 1 e 4, possibilitando uma interacção entre as porfirinas. Os hemos $2 \mathrm{e}$ 3 e os hemos 4 e 5 estão dispostos de uma forma muito semelhante e são praticamente perpendiculares entre si. Os nios carbonilo da cadeia polipeptídica e

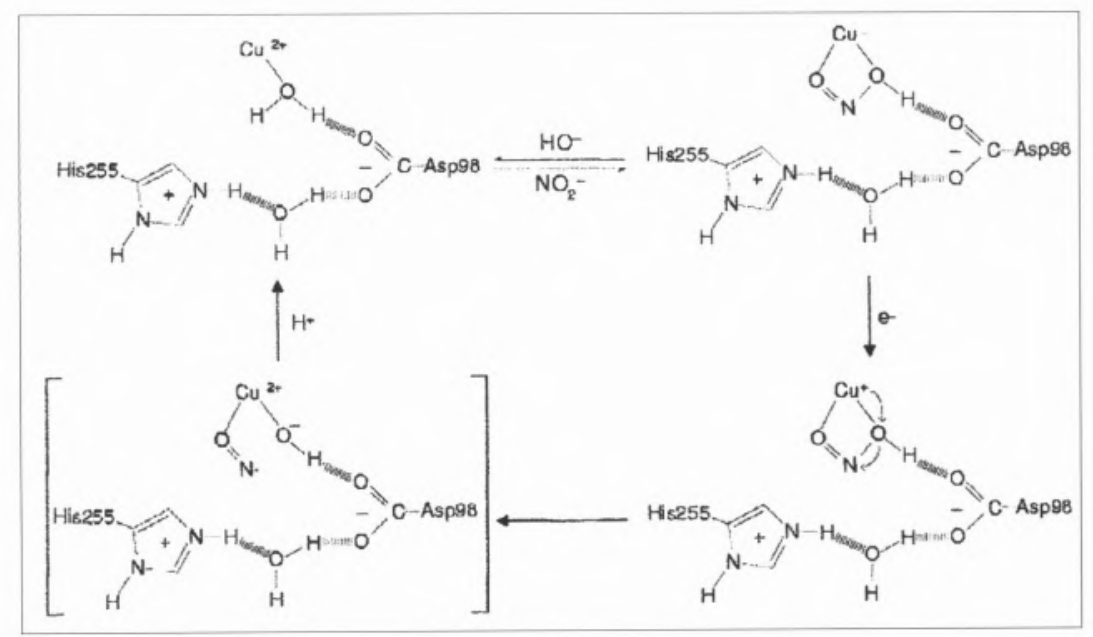

figura 18 Mecanismo de catálise da CuNiR de A. cycloclastes (Adaptado de Adman e Murphy, 2001). 

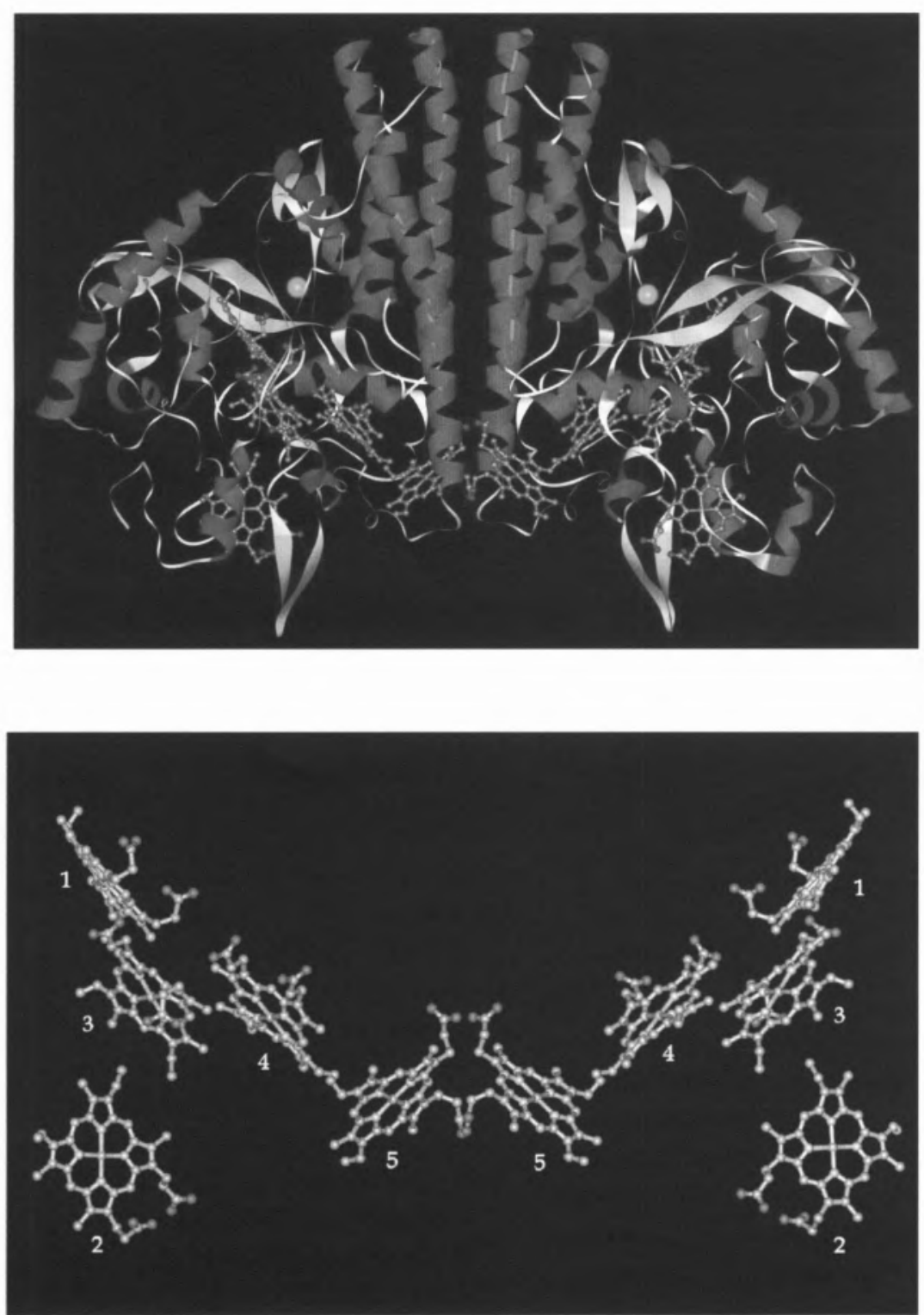

dois propionatos do hemo 1 apontam para o centro da molécula, participando na formação do sítio activo, enquanto que os propionatos do hemo 3 estabelecem ligações, por pontes de hidrogénio, com resíduos interiores da cadeia polipeptídica; os propionatos dos hemos 2 , 4 e 5 estão expostos à superfície, interactuando com o solvente (figura 20) (Einsle, 2001).

Com excepção do hemo catalítico (hemo 1) o arranjo espacial dos restantes hemos define dois tipos de interacção entre os hemos: interacção entre hemos quase perpendiculares, em forma de cotovelo, e interacção entre hemos paralelos. 0 primeiro tipo de interacção, entre os hemos $2 / 3$ e os hemos $4 / 5$, é comum a uma série de ci- tocromos multihémicos (hemos 2/3, 5/6 e 7/8 da OHA - passo 3, citocromo c3 e citocromo $C_{554}$ ); no entanto, as suas propriedades não estão ainda completamente estabelecidas. 0 segundo tipo de interacção, entre os hemos $3 / 4$, é também encontrado numa variedade de enzimas (hemos 1/2, 3/5, 6/7 da OHA passo 3 , citocromo $C_{554}$ e citocromo c split-Soret de D. desulfuricans) e permite uma interacção directa das porfirinas. 0 padrão definido é tal que as disposições perpendiculares dihémicas estão ligadas entre si por um empilhamento paralelo entre hemos (Einsle, 2001).

A estrutura de Raios-X, obtida para Wolinella succinogenes e mais recentemente a estrutura de Raios-X da ccNiR de $D$. desulfuricans ATCC 27774 reve- figura 19 Representação esquemática da estrutura da ccNiR de S. deleyianum. Os hemos e o ião cálcio (a verde) estão representados por modelos "stick and ball" (Adaptado de Einsle, 2001) figura 20 Representação e orientação relativa dos hemos na ccNiR de S. deleyianum (Adaptado de Einsle, 2001). lam uma elevada homologia com a descrita anteriormente (S. deleyianum) (Einsle et al., 1999; Lampreia et al., 2000; Moura e Moura, 2001).

A redução do nitrito $\left(\mathrm{NO}_{2}^{-}\right)$ocorre no lado distal do hemo 1; vários ligandos contribuem para uma densidade positiva desta cavidade, justificando deste modo a preferência na utilização de substratos aniónicos. Os resíduos que formam o sítio activo funcionam tanto como reservatório (a reposição é efectuada por moléculas de água), como doadores de protões na redução a amónia, para além de interactuarem com o substrato, estabilizando-o. No entanto, se esta cavidade positiva facilita a entrada do substrato aniónico, o mesmo não acontece relativamente ao produto for- 
figura 21 Representação esquemática da estrutura da N2OR de Ps. nautica 617. Os centros de cobre estão representados por modelos "stick and ball" (Adaptado de Brown et al., 2000).

mado, a amónia $\left(\mathrm{NH}_{4}+\right)$. A existência de um segundo canal, em oposição ao anterior, preenchido com moléculas de água e com uma densidade negativa na superfície da molécula, favorece a saída do produto formado. A existência de dois canais separados, para o substrato e para o produto, permite o fluxo direccionado dos metabolitos através da proteína, evitando deste modo a inibição pelo produto e contribuindo para a elevada especificidade da ccNiR (Einsle et al., 1999; Einsle, 2001; Moura e Moura, 2001).

\subsubsection{Redutase do óxido nítrico (passo 7) - NOR}

A redutase do óxido nítrico (NOR) é uma enzima membranar que catalisa a conversão de duas moléculas de óxido nítri-

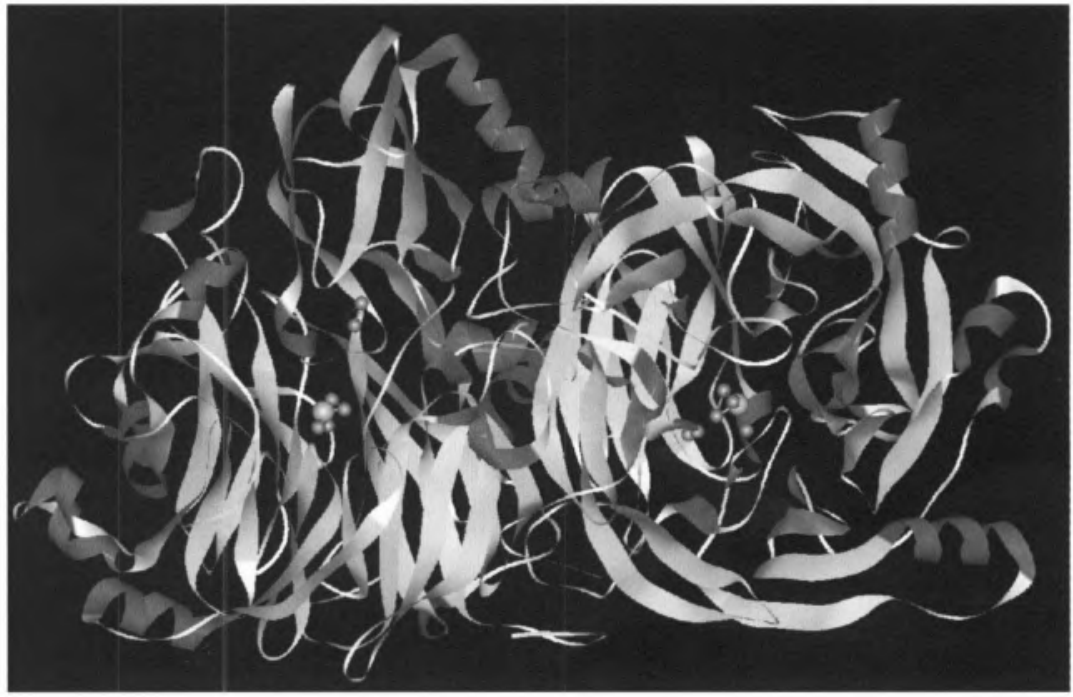

co (um intermediário tóxico) em óxido nitroso, de acordo com a seguinte equação:

$2 \mathrm{NO}+2 \mathrm{H}^{+}+2 \mathrm{e}-\rightarrow \mathrm{N}_{2} \mathrm{O}+\mathrm{H}_{2} \mathrm{O}$

Dada a sua instabilidade, o que torna a purificação difícil, a NOR é uma das enzimas menos caracterizadas. É um complexo $b c$ semelhante à oxidase do citocromo c (COX), mas que não contém cobre (Girsch e de Vries, 1997; Sakura e Sakurai, 1997; Cheesman et al., 1998). É um heterodímero que contém, na subunidade maior, dois hemos b, um de spin baixo (com uma coordenação Met-His) e um de spin alto, e um ferro năo hémico e, na subunidade menor, membranar, um hemo $c$ (com uma coordenaçăo Met-His) funciona como local de entrada dos electrões na enzi- ma. A subunidade maior possui 12 hélices transmembranares e liga o centro catalítico, um centro dinuclear de ferro, formado pelo hemo $b$, de spin alto, e o ferro não hémico (coordenado a três histidinas), acoplados antiferromagneticamente por um oxo/hidroxo em ponte (ligando do hemo b); o ferro não hémico ocupa a posição do cobre (CuB) nas COX. O hemo $b$ de spin baixo e o hemo C funcionam como mediadores nas transferências intra e intermolecular, respectivamente (Girsch e de Vries, 1997; Cheesman et al., 1998; Hendriks et al., 1998).

Por semelhança com a COX, o mecanismo proposto envolve, após ligação, em ponte, da primeira molécula de óxido nítrico (NO) em ponte aos dois ferros, a redução de ambos os centros, seguida

figura 22 (A) Representação do centro catalítico CuZ e as sete histidinas que o coordenam, (B) centro binuclear de cobre, CuA e respectivos ligandos, da N2OR de Ps. nautica 617 (Adaptado de Brown et al., 2000).

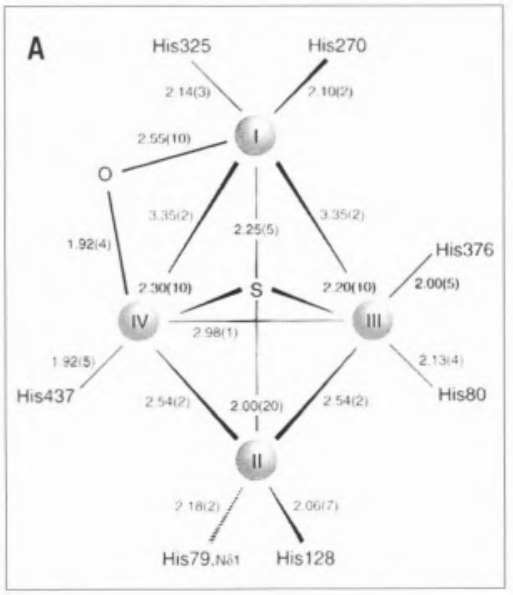

B

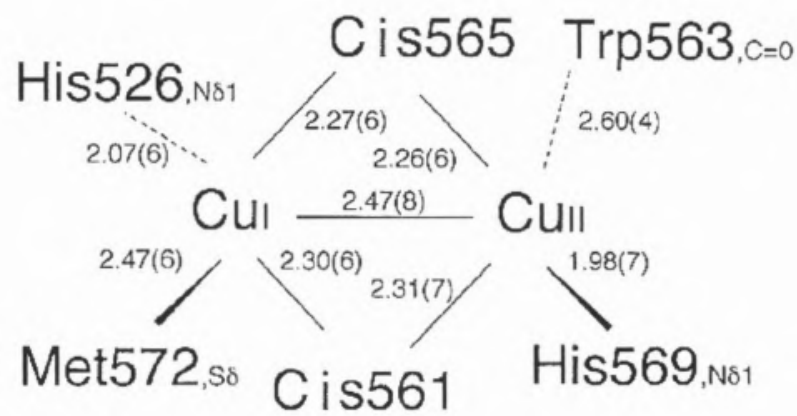




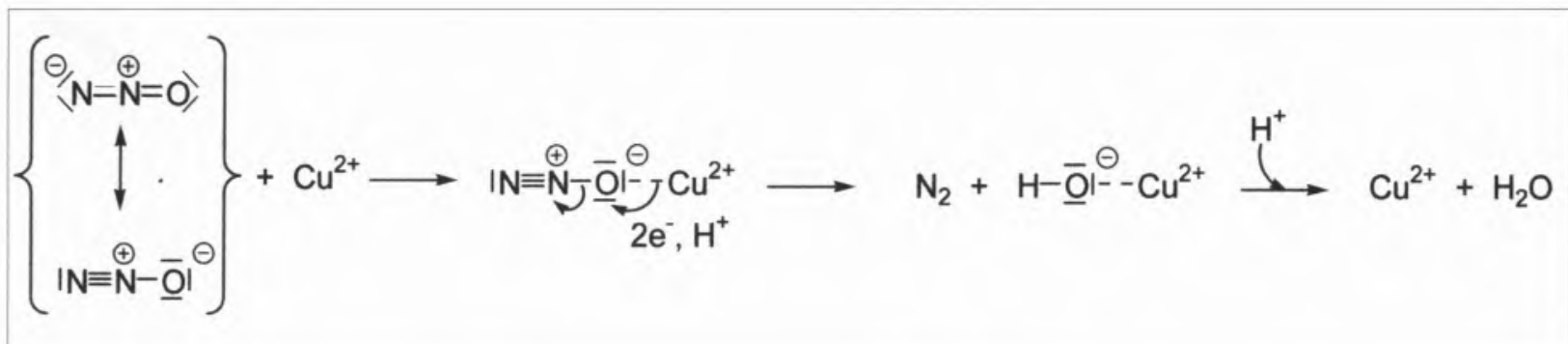

figura 23. Mecanismo de catálise da N2OR de Ps. nautica 617 (Adaptado de Brown et al., 2000).

pela protonação do ligando em ponte, que sai sob a forma de água. A ligação da segunda molécula de NO resulta na quebra da ligação em ponte entre os dois ferros, pelo que cada um deles liga uma molécula de NO. A proximidade das duas moléculas de NO possibilita a formação da ligação N-N. A redução de um dos oxigénios do intermediário $\left(\mathrm{N}_{2} \mathrm{O}_{2}\right)$ permite o restabelecimento da ligação em ponte e a libertação do produto $\left(\mathrm{N}_{2} \mathrm{O}\right)$.

As diferenças estruturais entre a COX e a NOR devem em parte reflectir a diferença química da respectiva reacção de catálise. Aparentemente, a NOR não é uma bomba de protões (Girsch e de Vries, 1997). No entanto, a NOR, isolada e purificada de Ralstonia (R.) eutropha (anteriormente denominada A/caligenes eutrophus), consiste em apenas uma subunidade de $75 \mathrm{kDa}$, que contém os dois citocromos b e o ferro não hémico, mas não possui o hemo $c$. Dada a presença de uma extensão no $\mathrm{N}$-terminal (280 aminoácidos), presente também nas oxidases do quinol, especula-se que a NOR de Ralstonia (R.) eutropha represente um novo tipo de oxidase do quinol (Cramm et al., 1999).

\subsubsection{Redutase do óxido nitroso (passo 8) - $\mathrm{N}_{2} \mathrm{OR}$}

A redutase do óxido nitroso $\left(\mathrm{N}_{2} \mathrm{OR}\right)$, uma enzima periplasmática, catalisa o último passo da desnitrificação, de acordo com a seguinte equação:

$\mathrm{N}_{2} \mathrm{O}+2 \mathrm{H}^{+}+2 \mathrm{e}-\rightarrow \mathrm{N}_{2}+\mathrm{H}_{2} \mathrm{O}$

Exceptuando a $\mathrm{N}_{2} \mathrm{OR}$ de Rhodobacter (Rb.) sphaeroides, que contém zinco e níquel, e a de Wolinella succinogenes, que tem como co-factor hemos, as res- tantes contêm apenas cobre. Na generalidade, são homodímeros que contêm dois centros binucleares de cobre $\left(\mathrm{Cu}_{A}\right.$ e $\mathrm{Cu}_{Z}$ ou $\mathrm{Cu}_{\text {cat }}$ ). $\mathrm{O}$ centro de cobre $\mathrm{Cu}_{A}$ ( $\mathrm{Cu}$ I/Cu II de valência mista), semeIhante à oxidase do citocromo $c$ (COX), é responsável pela transferência electrónica, a partir de um doador externo para o centro catalítico, $\mathrm{Cu}_{2}$, com uma esfera de coordenação de cisteínas (Prudêncio et al., 2000; Moura e Moura, 2001).

A obtenção da estrutura de Raios-X da $\mathrm{N}_{2} \mathrm{OR}$ de PS. nautica 617 veio revelar que esta enzima não é constituída por dois centros binucleares de cobre; 0 centro de cobre $\mathrm{CuZ}$ pertence a uma nova classe de agregados em que quatro átomos de cobre estão coordenados a sete histidinas. Apenas um cobre (CulV) participa na ligação do substrato, os restantes actuam como reservatórios electrónicos, assegurando a rápida transferência e evitando a formação de produtos sem saída (Brown et al., 2000; Prudêncio et al., 2000).

A $\mathrm{N}_{2} \mathrm{OR}$ de PS. nautica 617 (figura 21) é um dímero no qual o domínio C-terminal de um dos monómeros interactua com o domínio $\mathrm{N}$-terminal do outro monómero, resultando numa proximidade entre os centros $\mathrm{Cu}_{A}$ e $\mathrm{Cu}_{Z}$ de subunidades diferentes. Dois resíduos do C-terminal (Met570 e Fen564) estabelecem interacções entre as duas subunidades e provavelmente estão envolvidos na transferência intraelectrónica. Cada monómero é composto por dois domínios distintos, formados por segmentos contíguos da cadeia polipeptídica. O N-terminal forma uma hélice de sete lâminas em folha b; cada lâmina é composta por quatro folhas b, antiparalelas e torcidas, dispostas radialmente, definindo uma cavidade central cónica. O C-terminal consiste em nove folhas b antiparalelas, com uma topologia em "Greek-key", típica das cupredoxinas (Brown et al., 2000).

O centro $\mathrm{Cu}_{z}$ (figura 22A) está localizado numa das extremidades da estrutura em hélice a e possui quatro cobres, dispostos num arranjo tetraédrico distorcido; Cul e Cull estão ligados a dois cobres, enquanto que Culll e CulV estão ligados a três cobres. Três dos cobres (Cul, Cull e Cullı) estão ligados a duas histidinas e apenas uma histidina coordena CulV. Os cobres Culll e CulV estão ligados em ponte por um enxofre inorgânico e um oxigénio liga em ponte os cobres Cul e CulV (Prudêncio et al., 2000; Moura e Moura, 2001).

No centro $\mathrm{Cu}_{\mathrm{A}}$ (figura 22B) os cobres binucleares estão ligados em ponte por duas cisteínas (Cis561 e Cis565); adicionalmente, uma histidina coordena cada um dos cobres (His526 e His569); uma metionina (Met572) e um triptofano (Trp563) completam a coordenação, quadrangular plana distorcida, do Cul e do Cull, respectivamente (Moura e Moura, 2001).

0 mecanismo de redução proposto (figura 23) envolve três passos: o cobre catalítico (CuIV) permanece oxidado e, como tal, disponível para ligar o substrato (N2O); a ligação do N2O ao cobre CulV ocorre através do átomo de oxigénio, sendo o átomo de azoto exterior estabilizado por interacções com a Lis397 e His376; o centro $\mathrm{Cu}_{2}$ comporta-se como um "tampão electrónico" (Moura e Moura, 2001). 


\section{Agradecimentos}

Os autores agradecem ao PRAXIS e COST apoio financeiro. Um agradecimento aos grupos de Química Bioinôrganica, Biofísica de Proteínas e Cristalografia de Proteínas do COFB/DQ por muitas contribuições. Ao Jorge Pereira pela ajuda na obtenção de inúmeras figuras.

\section{Bibliografia}

- Adman, E.T., Murphy, M.E.P. (2001) "Copper nitrite reductase" in Handbook of Metalloproteins, (A. Messerschmidt, R. Huber, T. Poulos, K. Wieghardt, Eds), Vol 2, pp 13811390, John Wiley \& Sons, LTD

- Allen, J.W.A., Ferguson, S.J., Fülöp, V. (2001) 'Cytochrome cdl nitrite reductase' in Handbook of Metalloproteins (A. Messers. chmidt, R. Huber, T. Poulos, K. Wieghardt, Eds), Vol 1, pp 424-439, John Wiley \& Sons, LTD

- Averill, B.A. (1996) "Dissimilatory nitrite and nitric oxide reductases", Chem. Rev. 96, 2951-2964

- Berks, B.C., Ferguson, S.J., Moir, J.W.B., Richardson, D.J. (1995) "Enzymes and associated electron transport systems that catalyse the respiratory reduction of nitrogen oxides and oxyanions", BBA, 1232, 97-173

- Brown, K., Tegoni, M., Prudêncio, M., Pereira, A.S., Besson, S., Moura, J.J.G., Moura, I., Cambillau, C. (2000) "A novel type of catalytic copper cluster in nitrous oxide reduc tase", Nature structural biology, 7, 191-195

- Bursakov, S., Liu, M.-Y., Payne, W.J., LeGall, J., Moura, I., Moura J.J.G. (1995) "Isolation and preliminary characterization of a soluble nitrate reductase from the sulphate reducing organism Desulfovibrio desulfuricans ATCC 27774", Anaerobe, 1, 55-60

- Carneiro C., Almendra M.J., Bursakov S. Liu M.-Y., Payne W.J., LeGall J., Moura J.J.G., Moura I. (1995) "Nitrate reductase from a sulfate reducing Desulfovibrio desulfuricans ATCC 27774", J. Inorg. Chem., 59 738

- Cheesman, M.R., Zumft, W.G., Thomson, A.J. (1998) "The MCD and EPR of the heme centers of nitric oxide reductase from Pseudomonas stutzeri: evidence that the enzyme is structurally related to the heme-copper oxidases", Biochem., 37, 3994-4000

- Cramm, R., Pohlmann, A., Friedrich, B. (1999) "Purification and characterization of the single-component nitric oxide reductase from Ralstonia eutropha", FEBS Lett., 460 6-10
- Cutruzollà, F., Arese, M., Grasso, S., Bellelli, A., Brunori, M. (1997) "Mutagenesis of nitrite reductase from Pseudomonas aerugi nosa: tyrosine 10 is not involved in catalysis*, Febs lett., 412, 365-369

- Dias, J.M., Bursakov, S., Carneiro, C., Moura, J.J.G., Moura, I., Romão, M.J. (1999 a) "Crystallization and preliminary $X$-ray analysis of a nitrate reductase from Desulfovibrio desulfuricans ATCC 27774", Acta Cryst., D55, 877-879

- Dias, J.M., Than, M.E., Humm, A., Huber, R., Bourenkov, G.P., Bartunik, H.D., Bursakov, S., Calvete, J., Caldeira, J., Carneiro, C. Moura, J.J.G., Moura, I., Romão, M.J. (1999 b) "Crystal structure of the first dissimilatory nitrate reductase at $1,9 \AA$ solved by MAD methods", Structure, 7, 65-79

- Einsle, O. (2001) "Cytochrome c nitrite reductase" in Handbook of Metalloproteins, (A. Messerschmidt, R. Huber, T. Poulos, K. Wieghardt, Eds), Vol 1, pp 440-453, John Wiley \& Sons, LTD

- Einsle, O., Messerschimdt, A., Stach, P. Bourenkov, G.P., Bartunik, H.D., Huber, R., Kroneck, P. (1999) "Structure of cytochrome c nitrite reductase", Nature, 400, 476-480

- Ferguson, S.J. (1998) "Nitrogen cycle enzymology", Current Opinion in Chemical Biology, 2, 182-193

- Girsch, P., de Vries, S. (1997) "Purification and initial kinetic and spectroscopic characterization of NO reductase from Paracoccus denitrificans", BBA, 1318, 202-216

- Hendriks, J., Warne, A., Gohlke, U., Haltia, T., Ludovici, C., Lübben, M., Saraste, M. (1998) "The active site of the bacterial nitric oxide reductase is a dinuclear iron center", Biochem., 37, 13102-13109

- Holmes, A.J., Costello, A., Lidstrom, M.E., Murrell, J.C. (1995) "Evidence that particula te methane monooxygenase and ammonia monooxygenase may be evolutionarily related", FEMS Microbiol Lett., 132, 203-208

- Igarashi, N., Tanaka, N. (2001) "Hidroxylamine oxidoredutase" in Handbook of Metalloproteins (A. Messerschmidt, R. Huber, T. Poulos, K. Wieghardt, Eds), Vol 1, pp 454470, John Wiley \& Sons, LTD

- Lampreia J., Moura J.J.G., Moura, I., Romão, M.J. (2000) "Crystallisation and preliminary $\mathrm{X}$-ray analysis of a membrane bound nitrite reductase from Desulfovibrio desulfuricans ATCC 27774", Acta Crystallogr D, 56, 215-217

- Lopes, H., Besson, S., Moura, I., Moura, J.J.G. (2001) "Kinetics of inter- and intramolecular electron transfer of Pseudomonas nautica cytochrome $c d_{1}$ nitrite reductase: regulation of the NO-bound end product", $J$. Biol. Inorg. Chem., 6, 55-62

- Madigan, M.T., Martinho, J.M., Parker, J.
(2000) Biology of microorganisms 9th edition. Prentice-Hall

- McTavish H., Fuchs, J.A., Hooper, A.B. (1993) "Sequence of the gene coding for ammonia monooxygenase in Nitrosomonas europaea", J.Bacteriol., 175, 2436-2444

- Moura, I., Bursakov, S., Costa, C., Moura, J.J.G. (1997) 'Nitrate and nitrite utilization in sulfate reducing bactéria', Anaerobe, $\mathbf{3}$. 279-290

- Moura, I., Moura, J.J.G. (2001) "Structural aspects of denitrifying enzymes", Current Opinion in Chemical Biology, 5, 168-175

- Prudêncio, M., Pereira, A.S., Tavares, P.. Besson, S., Cabrito, I., Brown, K., Samyn, B., Devreese, B., Van Beeumen, J., Rusnak, F., Fauque, G., Moura, J.J.G., Tegoni, M., Cambilau, C., Moura, I. (2000) "Purification, characterization and preliminary crystallographic study of copper-containing nitrous oxide reductase from Pseudomonas nautica 617. Biochem., 39, 3899-3907

- Richardson, D.J., Watmough, N.J. (1999) "Inorganic nitrogen metabolism in bacteria", Current Opinion in Chemical Biology, 3 207-219

- Richardson, D.J., Wehrfritz, J.M., Keech, A., Crossman, L.C., Roldan, M.D., Sears, H.J., Butler, C.S., Reilly, A., Moir, J.W.B., Berks, B.C., Ferguson, S.J., Thomson, A.J., Spiro, S. (1998) "The diversity of redox proteins involved in bacterial heterotrophic nitrification and aerobic denitrification", Biochem. Soc. Trans., 26, 401-408

- Romāo, M.J., Dias, J.M., Moura, I. (2001) "Dissimilatory nitrate reductase" in Handbook of Metalloproteins (A. Messerschmidt, R. Huber, T. Poulos, K. Wieghardt, Eds), Vol 2. pp 1075-1085, John Wiley \& Sons, LTD

- Romāo, M.J., Knäblein, J., Huber, R. Moura, J.J.G. (1997) "Structure and function of molybdopterin containing enzymes", Prog. Biophys. molec. Biol., 68, 121-144

- Sakurai, N., Sakurai, T. (1997) "Isolation and characterization of nitric oxide reductase from Paracoccus halodenitrificans", Biochem., 36, 13809-13815

- Schmid, B., Chiu, H.-J., Ramakrishnan, V. Howard, J.B., Rees, D.C. (2001) "Nitrogenase" in Handbook of metalloproteins (A. Messerschmidt, R. Huber, T. Poulos, K. Wieghardt, Eds), Vol 1, pp 1025-1036, John Wiley \& Sons, LTD

- Sun, P.D., Boyington, J.C., Stadtman, T. (2001) "Formate dehydrogenase $\mathrm{H}^{\prime}$, in Handbook of Metalloproteins (A. Messerschmidt, R. Huber, T. Poulos, K. Wieghardt, Eds), Vol 2, pp 1109-1120, John Wiley \& Sons, LTD

- Zumft, W.G. (1997) "Cell biology and molecular basis of denitrification". Microbiol. Mol. Biol. Rev., 61, 533-616 